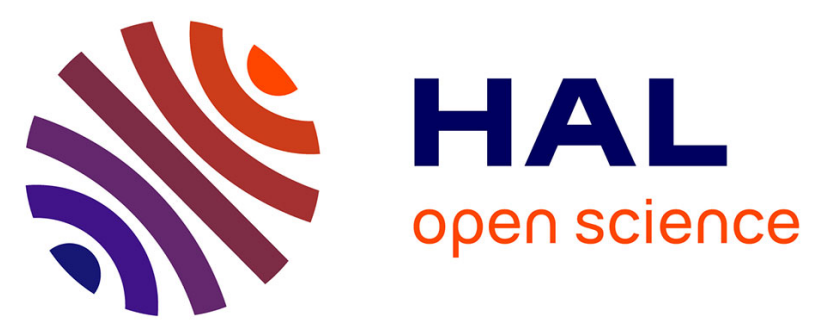

\title{
New taxa of the water mite family Limnocharidae (Actinotrichida: Eylaoidea) parasitising tropical water bugs of the genus Rhagovelia Mayr, 1865 (Hemiptera: Veliidae) reveal unsuspected diversity of larval morphologies
}

Reinhard Gerecke, Andreas Wohltmann, Bruce P Smith, Mark Judson

\section{To cite this version:}

Reinhard Gerecke, Andreas Wohltmann, Bruce P Smith, Mark Judson. New taxa of the water mite family Limnocharidae (Actinotrichida: Eylaoidea) parasitising tropical water bugs of the genus Rhagovelia Mayr, 1865 (Hemiptera: Veliidae) reveal unsuspected diversity of larval morphologies. Aquatic Insects, 2020, 41 (4), pp.273-323. hal-03019333

\section{HAL Id: hal-03019333 \\ https://hal.sorbonne-universite.fr/hal-03019333}

Submitted on 23 Nov 2020

HAL is a multi-disciplinary open access archive for the deposit and dissemination of scientific research documents, whether they are published or not. The documents may come from teaching and research institutions in France or abroad, or from public or private research centers.
L'archive ouverte pluridisciplinaire HAL, est destinée au dépôt et à la diffusion de documents scientifiques de niveau recherche, publiés ou non, émanant des établissements d'enseignement et de recherche français ou étrangers, des laboratoires publics ou privés. 
New taxa of the water mite family Limnocharidae (Actinotrichida: Eylaoidea)

parasitising tropical water bugs of the genus Rhagovelia Mayr, 1865 (Hemiptera:

Veliidae) reveal unsuspected diversity of larval morphologies

Reinhard Gerecke

Andreas Wohltmann ${ }^{b}$

Bruce P. Smith

Mark Judson ${ }^{d}$

\section{CONTACT}

a Institut de Systématique, Évolution, Biodiversité (ISYEB), UMR 7205 CNRS, MNHN, UPMC, EPHE, Muséum national d'Histoire naturelle, Sorbonne Universités, 57 rue Cuvier, CP 53, FR 75005 Paris (France) and University of Tübingen, Department of Evolution and Ecology, Auf der Morgenstelle 28E, DE 72076 Tübingen (Germany) (current contact address: Biesingerstr. 11, DE 72070 Tübingen); email: reinhard.gerecke@uni-tuebingen.de. Corresponding author.

b Findorffstr. 11, DE 27721 Ritterhude, Germany; email: andreas.wohltmann@t-online.de.

c Department of Biology, Ithaca College, Ithaca NY 14850 USA, Professor Emeritus, (current contact address: 118 Sunset Drive, Perth ON K7H 3C7 Canada); email: parasitengona@gmail.com; website: https://faculty.ithaca.edu/smithb/. 
d Institut de Systématique, Évolution, Biodiversité (ISYEB), UMR 7205 CNRS, MNHN, UPMC, EPHE, Muséum national d'Histoire naturelle, Sorbonne Universités, 57 rue Cuvier, CP 53, FR 75005 Paris (France); email: mark.judson@mnhn.fr.

\section{ABSTRACT}

The larval stage of Neolimnochares johnstoni Smith and Cook, 2005 is first described in detail, the larva of a similar undescribed species, Neolimnochares sp. B, see Table 1, is recorded from Peru. Larvae attributed to Limnochares (Cyclothrix) australica Lundblad, 1941a by Martin and Smit (2002) are considered to belong to Neolimnochares Lundblad, 1941c. Neolimnocharinae subfam. n. is proposed and discussed. For larvae assigned to this subfamily, parasitic on veliid water bugs (Rhagovelia Mayr, 1865) and with extraordinary morphological modifications, new taxa are proposed: Veliacola gen. n., (V. mirificus sp. n., Madagascar); Archaeveliacola gen. n. (A. papuanus sp. n., Indonesia, A. smiti sp. n., Australia); Armaveliacola gen. n. (A. rhagoveliae sp. n., Madagascar, A. major sp. n., Madagascar, A. minor sp. n., Cameroon, Kenya); Isoveliacola gen. n. (I. costaricensis sp. n., Costa Rica, I. borneoensis sp. n., Indonesia). Additional records are: Veliacola sp. (Dominican Republic), Archaeveliacola sp. (Bolivia), and Isoveliacola sp. (Belize). Neolimnochares (Paracyclothrix) Lundblad, 1967 is synonymised with Limnochares (Cyclothrix) Wolcott, 1905, resulting in Limnochares (Cyclothrix) hyaliniseta (Lundblad, 1969) comb. n., and L. (C.) longimaxillaris (Lundblad, 1969) comb. n. (both Myanmar).

Running Title: Water mite larvae parasitising Rhagovelia

KEYWORDS water mites; Neolimnocharinae subfam. nov.; taxonomy; parasitism; Veliidae

\section{Introduction}

As early as the first treatment of water mites from Madagascar, we find a brief description by Koenike (1898: 300) of a water mite larva 'von auffallendem Körperbau' (with an outstanding body-form). He stated that E. Trouessart would illustrate it in 'Grandidier's large work on the fauna of Madagascar' (presumably a reference to the latter's Histoire physique, naturelle et politique de Madagascar), but this did not happen. Koenike's strange larva was largely forgotten, apart from a brief mention in K. Viets (1953), until its rediscovery in the Muséum national d'Histoire naturelle, Paris (MNHN), on a slide (19C12) labelled 'Collection Trouessart, Larves de Hydrachnide, Collection Alluaud sur Velia, Diégo Suarez 
Madagascar' (Gerecke 2004). This slide contains eight specimens representing two closely related species, which are described here as Armaveliacola rhagoveliae gen. n. sp. n. (one specimen) and A. major sp. n. (7 specimens). Both show the morphological features mentioned by Koenike: a largely protruding gnathosoma, bearing short palps on its ventral surface; a pair of short, movable 'sclerite clubs' at its anterior margin; the anterior pair of legs inserting at the junction between the gnatho- and idiosoma; legs II and III each at the posterior edge of an extension of the body margin; each leg with two claw-like structures - a heavy, strongly curved claw and an elongate, weakly curved empodium; venter with 3 transverse lines of ctenidia. Concerning the ambulacrum of early-derivative water mite larvae, different interpretations have been published: Koenike (1898) erroneously interpreted the empodium as 'a ramus of the leg claw'.

The current state of preservation of the specimens described by Koenike (1898) is sufficient for recognising outstanding character combinations, but too poor (compressed, mounting medium partly dried out) for a detailed description. Consequently, several attempts were made to gain further specimens by new searches in the field and in museum collections.

Notwithstanding the lack of precise details concerning the original collecting site, it is probable that the specimens in question came from the Montagne d'Ambre, a forested area frequented by numerous hunters and biologists during their visits to Antsiranana (formerly Diégo Suarez), which has been protected as a National Park since 1985.

A survey of the aquatic Heteroptera in the entomological collection of MNHN allowed the detection of a further ten specimens of Koenike's larvae. They were found exclusively in the dry material, still attached to their hosts of the genus Rhagovelia Mayr, 1865, in Alluaud's collections from Antsiranana (Figures 1a-b), without more detailed locality information. It is symptomatic of the undetected taxonomic richness of Madagascar that new field work undertaken in 2011, instead of producing further Armaveliacola larvae, resulted in the detection of an additional previously unknown larval morphotype described here as Veliacola mirificus gen. n. sp. n., again parasitising veliid bugs. During research in the past decade, additional larval specimens of related species were found at the Vienna Museum of Natural History (NHMW), the Bavarian State Collection, Munich (ZSM), the Smithsonian Institution, Washington (USNM) and MNHN. The present paper aims to clarify the taxonomic position of the water mite larvae parasitising Veliidae. Laboratory rearing of parasitic larvae to 
deutonymphs identified as Neolimnochares johnstoni Smith and Cook, 2005 permitted the first correlation for a member of this genus. Comparison with the other larvae described here in turn allowed their plausible attribution to the family Limnocharidae.

\section{Material and methods}

\section{Museum collections and field work}

\section{Museum collections}

Water bugs were examined for larvae in the following institutions, and the following abbreviations are used:

Canadian National Collection, Ontario (CNCO): Specimens sampled in Ontario, Canada, by B.P. Smith.

Muséum national d'Histoire naturelle, Paris (MNHN): The slide in the Trouessart collection containing the mite larvae, collected by Alluaud and examined by Koenike (1898), was rediscovered during a PARSYST project on the water mite fauna of Madagascar (Gerecke 2004). During the course of further investigations in 2011, in the framework of the EUSYNTHESYS project, these specimens were studied in more detail and the collection of African aquatic Heteroptera in the Entomological Department of the MNHN (curator E. Guilbert) was surveyed for additional material. A total number of 46 boxes with dry material (eight of them reserved for aquatic families) and four jars with ethanol-preserved specimens from coll. Millot (1946-1948) were screened for further specimens parasitised by mite larvae. The dry material produced material of Armaveliacola major (5 larvae), A. minor sp. n. (1 larva) and A. rhagoveliae (1 larva); in the liquid collection, only Nepomorpha parasitised by hydrachnid larvae were found, but no material of interest for this study.

Naturhistorisches Museum Wien (NHMW): Veliidae collection, 5 boxes, plus alcohol material (curator: H. Zettel). Parasitic larvae representing four species were found: Isoveliacola costaricensis sp. n., I. borneoensis sp. n., Armaveliacola major and A. minor; details of collection dates, locations and hosts are listed in the species descriptions. The following material of Rhagovelia was screened but no parasitic water mites were found: about 500 unidentified specimens in ethanol, Madagascar: Majunga, 1997, Fianarantsoa (Ranomafana), 1998, P. Pacholàtko leg.; about 1000 unidentified specimens in ethanol, various sites in all provinces, 2001, R. Gerecke and T. Goldschmidt leg.; about 100 unidentified specimens, dry 
mounted, Philippines, various years, H. Zettel et al. leg.; numerous specimens of $R$. samardaca J. Polhemus and D. Polhemus, 1988 and R. silau J. Polhemus and D. Polhemus, 1988, Indochina, various sites; of $R$. sumatrensis Lundblad, 1933, Thailand, various sites; of R. seychellensis Lundblad, 1936, Seychelles, various sites.

Ohio State University, Columbus (OSU): A photograph and information on a single larva on unidentified veliid from Belize were provided by Hans Klompen.

Queensland Museum, Australia (QMS): Site of deposition of the holotype of Archaeveliacola smiti sp. n.

Senckenberg Museum, Frankfurt (SMF): The entire water bug collection, distributed over 10 boxes. No parasitic water mites could be found on Veliidae.

Smithsonian Institution, Washington (USNM): The entire water bug collection, comprising about 50 entomological boxes (curator: T.J. Henry). Parasitic and phoretic larvae of several mite taxa were detected, including three species of Neolimnocharinae. Unfortunately, this material is in a too poor state for taxonomic descriptions, but it provides interesting zoogeographical information (see results).

Zoologische Staatssammlung München (ZSM): Veliidae collection, liquid material from recent field work in Indonesia (curator: M. Balke). Parasitic larvae were found on Rhagovelia specimens from two sites in Papua Barat. Final destination: Museum Zoologicum Bogoriense, Cibinong, Indonesia (MZB).

Field work

Field work in northern Madagascar (Antsiranana Province) was undertaken from March to April 2011, in cooperation with R. Oliarinony and R. Ranaivosolo (Antananarivo) and Giorgio Sabella (Catania). Sampling was mostly carried out in the rain forest belt of the Montagne d'Ambre, but also in habitats in the gallery forest surrounding Lake Farihy Makery (near Sakaramy). A second part of the field trip was dedicated to the sampling of streams and springs in natural forest areas in central-eastern Madagascar (Antananarivo and Fianarantsoa provinces), in cooperation with F. Rakotondraparany, J. Rasamy, W. Pflüger (University of Antananarivo) and J. Ranaivo (Centre Vahatra, Antananarivo). Water insect collecting was done with a benthos hand net and concentrated on stream-pool surfaces of small streams, the typical habitat of Veliidae (commonly known as riffle bugs). In order to detect potential adults 
of the veliid-parasitising larvae, benthic collections concentrated on aquatic and semi-aquatic biotopes surrounding stream pools (remnant pools, riparian accumulations of leaf litter, interstitial sand and gravel, riffles and cascades). In order to have the possibility to conduct both morphological and molecular studies on the material from this trip, all the specimens were conserved in 95\% undenaturated ethanol.

Mite larvae detected during field work and museum studies were detached from their host after documentation of the attachment sites. For each mite genus described below, at least one specimen was selected for SEM investigation. In the case of Veliacola mirificus, the specimen was investigated in the electron microscope both before and after detachment. In the case of Armaveliacola major, parasitic mite larvae were photographed with a high-resolution camera under the stereo microscope before detachment (Figures 1a-b), while SEM observations were only made after detachment of the selected specimen (Figure 8).

One specimen each of Veliacola mirificus, Armaveliacola major, and Archaeveliacola papuanus sp. n. was selected for molecular analysis. DNA extraction was done in a nondestructive manner, conserving the exoskeleton and appendages for post-extraction morphological study. In the case of Veliacola mirificus, for which only two specimens were available in total, this exoskeleton remains the only one available for light microscopy and was designated the holotype, the other being mounted on a stub for SEM studies. In the case of Armaveliacola, in addition to the exoskeleton of $A$. major left over after DNA extraction, a further specimen was prepared and slide-mounted in Hoyer's fluid, and further two specimens (one from Madagascar and one from Cameroon) are now conserved in $100 \%$ ethanol as undissected specimens in MNHN.

In all cases, attempts to obtain useable DNA sequences were unsuccessful.

Larvae of Neolimnochares johnstoni were identified on the basis of pharate deutonymphs removed from within larval cuticles and by keeping parasitised hosts in the laboratory until deutonymphs had emerged from the protonymph.

\section{Morphological studies}

For measurements and drawings, selected specimens were dissected under a stereomicroscope and studied under a light microscope (Olympus BH-2 with differential interference contrast and camera lucida). In the drawings, idiosomal and gnathosomal sclerites are indicated by 
stippling, which is not meant to reflect the surface structure of sclerites. In some species the sclerites appeared to be naturally rugose, but in specimens sampled a long time ago, fixation media have clearly modified the surface structure of sclerites. Drawings of legs are always given in anterolateral view.

Examination of specimens in polarised light was carried out using a Leitz Laborlux S microscope, with a rotating stage, to determine the presence of actinopilin, which is strongly birefringent (Grandjean, 1935a, 1935b, 1970). Photographs were taken at partial extinction, such that the surrounding structures are still visible (Figure 10). The optical sign of the birefringent material was determined using a full-wave $(\lambda)$ plate.

For SEM studies, one or more specimens of five taxa were critically point dried, sputtercoated and then observed in a Zeiss Evo LS10 scanning electron microscope.

\section{Morphological abbreviations and terminology}

For an explanation of the general morphological terminology of parasitengone larvae and of standard abbreviations, see Wohltmann et al. (2007) - an additional abbreviation is ics (infracapitular shield, covering the distal gnathosoma dorsally). For reasons discussed below, the unusual structures found on the leg coxae of most neolimnocharines are interpreted as modified setae and are therefore designated according to their inferred homologies with ordinary setae of other groups. These modified setae are of four types. The club-like seta on coxa I of Armaveliacola (Figure 8e) is referred to as a clavate seta. The thickened setae with finger-like apical processes on coxa I of Veliacola (Figure 5o) are termed palmate setae. Broadened setae with multiple tines, resembling combs (Figure 8c), are termed ctenidial setae. The band-like setae on coxae II and III of Veliacola, which are smooth and lack tines (Figures 5g, o), are called taeniform setae. A measurement associated with a seta name refers to the length of the seta; data are given as minimum-maximum values in the text and Table 2. The genera are described in the order in which they appear on the cladogram of relationships (Figure 11). 


\section{Results}

\section{Superfamily Eylaoidea Leach, 1816}

The family Eylaidae and coordinate names have previously been attributed to Leach ' 1815 ', but this is incorrect because the paper in which the family was originally proposed (Leach, 1816) was published on 24 Jan. 1816 (Raphael 1970).

\section{Family Limnocharidae Grube, 1859}

\section{Diagnosis}

Typical Eylaoidea with two Claparède's organs $(c l p)$ at anterior margin of each coxa II, coxal plate I bearing 1-2, and both coxal plates II and III only 1 seta each; one trichobothrium on each telofemur of legs I-III; tarsus at legs I-III with one empodium and one claw. Setae K on genua I-III prominent.

\section{Remarks}

Diagnostic characters for larval Limnocharidae have been given by Wainstein (1980), Tuzovskij (1987) and Smith et al. (2010). As in all members of the superfamily Eylaoidea, the dorsal plate of limnocharid larvae is large (in unfed larvae covering well over one-third length of idiosoma), with setae $P M$ situated near midlength, and lateral eyes lie on each side on a single eye plate. In comparison with representatives of the other families, limnocharid larvae are characterised by reduced coxal setae numbers, and by leg tarsi bearing two dissimilar clawlike structures. In larvae of other eylaoid families, on each side 2 setae per coxal plate are found, and legs have paired claws plus an unpaired empodium.

Information on larval morphology is available for the following limnocharid species:

Subfamily Limnocharinae Grube, 1859

Limnochares sp. Vercammen-Grandjean (1980).

Limnochares (Limnochares) aquatica (Linnaeus, 1758). Sparing (1959 and references therein), Böttger (1972), Wainstein (1965, 1980).

Limnochares (Cyclothrix) americana Lundblad, 1941b. Crowell (1963), Prasad and Cook (1972), Prasad (1982a, 1982b).

Limnochares (Cyclothrix) crinita Koenike, 1898. Wiles (1993).

Laterolimnochares Jin, 1999. No description of the larval stage is available at present for species of the genus. 


\section{Subfamily Neolimnocharinae (subfam. n.)}

Neolimnochares sp. Martin and Smit (2002), misidentified as Limnochares (Cyclothrix) australica Lundblad, 1941a, see remarks below under Neolimnocharinae.

Subfamily Rhyncholimnocharinae Lundblad, 1936

Rhyncholimnochares kittatinniana Habeeb, 1954. Smith (1989b).

Austrolimnochares Harvey, 1998. No description of the larval stage is available at present for species of the genus.

\section{Subfamily Neolimnocharinae subfam. $n$.}

\section{Diagnosis}

Larva. Limnocharidae with dorsal gnathosomal shield formed by dorsal part of infracapitulum. Dorsum of idiosoma with a prominent scutum carrying 4 pairs of normal setae ( $A L, A M, P L, P M$, no trichobothria). Setae $\mathrm{h}_{1}$ (when present) situated on a common sclerite. Claparède's organs at least doubled. Leg claws proximally enlarged at least on legs I and II. Coxal setae simple or hypertrophied and strongly modified.

Postlarval instars. Palp usually four segmented due to fusion of femur and tibia - no evidence for more reliable characters (see discussion).

Type genus

Neolimnochares Lundblad, 1941c.

\section{Remarks}

The derivation of the generic name Neolimnochares was not explained by Lundblad (1937,

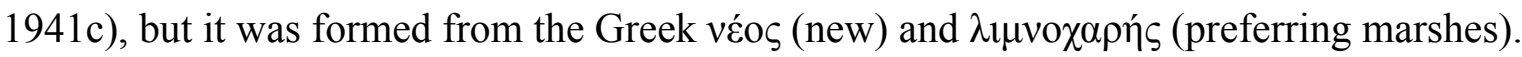

The definition of Neolimnocharinae is mainly based on larval characters (for a discussion of differences at this stage between Limnocharinae, Rhyncholimnocharinae and Neolimnocharinae, see below: 'Relationships to other water mite taxa'). The only character so far applied for separating deutonymphs and adults from other limnocharids is the fusion of palp femur and tibia (Cook 1974). However, this fusion is sometimes incomplete or shows variations within species or individuals - see Lundblad 1969 for Limnochares hyaliniseta Lundblad, 1969, and the discussion of the topic by Bader (1978). Moreover, the fusion of palp segments occurs frequently within water mites in general. The phylogenetic value of this 
character and the monophyly of the genus Neolimnochares have therefore been questioned (Cook 1974, Smith and Cook 2005b).

Paracyclothrix Lundblad, 1967 (type species Neolimnochares (Paracyclothrix) tenasserimensis Lundblad, 1967, by monotypy) was proposed as a subgenus of Neolimnochares and comprised three species characterised by the presence of swimming setae similar to those already known from deutonymphs and adults of the subgenus Limnochares (Cyclothrix) Wolcott, 1905 (type species Limnochares crinita Koenike, 1898, by original designation). The swimming behaviour, described in detail for Limnochares (Cyclothrix) americana (Smith and Barr 1977, Barr and Smith 1979), is unique within water mites and it is therefore reasonable to suppose that swimming within Limnocharidae has evolved independently to that of other water mite taxa. Therefore, it is unlikely that this type of swimming evolved two times convergently within the Limnocharidae and we propose Paracyclothrix to be a synonym of Cyclothrix. This synonymy results in two new subgeneric assignments: Limnochares (C.) hyaliniseta Lundblad, 1969 and L. (C.) longimaxillaris (Lundblad, 1969), both of which are known from Asia (Myanmar) and from the adult instar only. The remaining species, Limnochares (Cyclothrix) tenasserimensis Lundblad, 1941a, returns to its original subgenus.

In the present state of knowledge, the subfamily Neolimnocharinae includes 25 species, of which nine are known only from the larval stage, 15 only from postlarval instars and one species from the larva, deutonymph and adult (Table 1).

\section{Genus Neolimnochares Lundblad, 1941}

Neolimnochares was first proposed by Lundblad (1937) for two species, but because a type species was not designated, this is a generic nomen nudum (ICZN, Article 13.3). The genus was first made available by Lundblad (1941c), who provided a brief diagnosis and designated the type species.

Type species

'Neolimnochares' placophora Lundblad 1937, designation by Lundblad (1941c). 


\section{Diagnosis}

Larva. Neolimnocharinae with bifid, distally elongate palp-tarsus. Paired Claparède's organs at anterior margins of each Cx-II. Coxal setae normal (setiform). Setae $\mathrm{h}_{1}$ on a common sclerite.

Postlarval instars. Legs without swimming setae.

\section{Distribution}

South America, North America, Africa, Asia, Australia (Table 1).

\section{Neolimnochares johnstoni Smith and Cook, 2005}

\section{Material examined}

The material is deposited in CNCO. All specimens were sampled in Ontario, Canada, and identified by B.P. Smith; removed from parasitised hosts ranging from early-stage larval engorgement to fully developed protonymphs with pharate deutonymphs; all slide mounted if not stated otherwise:

1 larva from 5th instar Aquarius conformis (Uhler, 1878), Hastings County (Co.), Skootamata River at picnic area by Highway 7, 19.VII.1984.

1 larva from Limnoporus dissortis Drake and Harris, 1930, Lanark Co., Beaver Dam Creek, located on Highway 7, ca. 23 km west of Perth, 19.VII.1984.

8 deutonymphs (slides) and 29 deutonymphs (in fluid) reared from multiple specimens of Limnoporus dissortis, Frontenac Co., swampy pools beside Opinicon Road, near stream from Stonehouse Lake into Rock Lake, west of Chaffeys Lock, 6-10.VIII.1986.

1 larva from 4th instar Gerris buenoi Kirkaldy, 1911, 1 larva from 4th instar G. buenoi, 1 protonymph (with pharate deutonymph) from 5th instar G. buenoi, Frontenac Co., channels around the periphery of Hebert Bog, 30.VII.1985.

1 larva from 4th instar Gerris buenoi, Nipissing District, Whitney, swampy margin of Upper Madewaska River, 20.VII.1984.

1 larva from Gerris comatus (Drake and Hottes, 1925) $q$, Nipissing District, Algonquin Provincial Park, Little Madewaska River below dam at Wildlife Research Station, 20.VII. 1984. 
1 protonymph (with pharate deutonymph) from Gerris buenoi, Nipissing District, Algonquin Provincial Park, Opeongo Lake Road, calm section of Costello Creek next to road, 20.VII. 1984.

1 larva from Gerris comatus ${ }_{+}$, Wellington Co., Elora, Grand River at Elora Gorge, 7.VIII. 1985.

Uncertain records (larvae without gnathosoma). 2 larvae from 4th instar Aquarius remigis (Say, 1832), Wellington Co., Guelph, Speed River near Gordon Street, 7.VIII.1985.

\section{Description}

Larva. Metric data given in Table 2. Colour in life red. Body length of larva 269-1290 $\mu \mathrm{m}$, depending on degree of engorgement (Figure 1c).

Dorsum (Figure 2a) with scutum approximately pentagonal, surface with setae $A M, A L, P M$ and $P L$ almost smooth. Paired eyes located on oval sclerites (length/width 25-36/16-25 $\mu \mathrm{m}$ ) at level of setae $P M$. Anterior lens diameter $11-16 \mu \mathrm{m}$, posterior lens diameter 8-11 $\mu \mathrm{m}$. Remaining part of dorsum with smooth, linearly plicate cuticle. Dorsal setae (44-50 $\mu \mathrm{m})$ barbed, arranged in rows and situated on plates or platelets (length/width $20-24 / 14-17 \mu \mathrm{m}$ ); C row with $\mathrm{c}_{1-} \mathrm{c}_{2}$; D row with $\mathrm{d}_{1-2} ; \mathrm{E}$ row with $\mathrm{e}_{1-2}, \mathrm{~F}$ row with $\mathrm{f}_{1-2}, \mathrm{H}$ row with $\mathrm{h}_{1-2}$; setae $\mathrm{h}_{1}$ located on a common posterior plate (length/width 23-27/30-33 $\mu \mathrm{m}$ ).

Venter (Figure 2b) dominated by large coxal plates of legs I-III. Coxa I with smooth setae $1 a$ $(23-32 \mu \mathrm{m})$ and $1 b(27-41)$. Coxa II with smooth seta $2 a(29-39 \mu \mathrm{m})$, coxa III with smooth seta $3 a(33-38 \mu \mathrm{m})$. Two Claparède's organs $(c l p)$ at anterior margin of each coxa II. Anal pore between coxae III surrounded by an undivided anal sclerite (length/width 43-47/36-44 $\mu \mathrm{m})$ bearing 2 smooth setae $(23-42 \mu \mathrm{m}) ; 1$ pair of barbed setae $p s(36-76 \mu \mathrm{m})$ laterad of anal sclerite.

Gnathosoma (Figures $2 \mathrm{c}-\mathrm{d}$ ) with anterior quarter covered dorsally by a gnathosomal shield (length/width 70-82/56-83 $\mu \mathrm{m}$ ), formed by dorsal part of infracapitulum (ics). Ventral part of gnathosoma with smooth setae $b s(8-11 \mu \mathrm{m})$ and $c s(20-30 \mu \mathrm{m})$. Chelicera typical, cheliceral blade fine, slightly curved. Around chelicerae is smooth cuticle. Palp formula 0-N-NN-NNNNNNN $\omega \zeta$. Palp femur large, carrying a setulose seta $(48-51 \mu \mathrm{m})$ in dorsolateral position, genu with 2 smaller, setulose setae (42-44 and 35-41 $\mu \mathrm{m})$. Tibia with 3 smooth setae (17-18 
$\mu \mathrm{m})$. Odontus bifid with elongate tips almost parallel. Tarsus with 4 pit-like setae $(1-2 \mu \mathrm{m}), 1$ eupathidium $(5-8 \mu \mathrm{m})$ and 1 solenidion $\omega(11-13 \mu \mathrm{m})$.

Leg chaetotaxy as in Table 3 and Figures $2 \mathrm{e}-\mathrm{g}$. Telofemur of each leg with 1 trichobothrium in dorsal position. Seta $\kappa$ on genua I-II, prominent. Tarsi I-III each with elongate, thin empodium and modified claw with a broadened base, about halfway along a fine hook.

Postlarval instars. see Smith and Cook (2005).

\section{Distribution}

Larval specimens in this study were collected in southern Ontario; Smith and Cook (2005b) recorded adults in northeastern North America from Wisconsin through Nova Scotia.

\section{Hosts}

Adults and various juvenile instars of Gerris buenoi, G. comatus, Limnoporus dissortis, Aquarius conformis (Hemiptera; Gerridae), and A. remigis. Attachment sites: on adult hosts most frequently membranous areas between mouthparts and anterior margin of prosternum (Figure 1c); on juvenile hosts quite commonly on the dorsal thoracic region (pronotum, mesonotum, wing pads, etc).

\section{Remarks}

The adult and deutonymphal stases of $N$. johnstoni were previously described by Smith and Cook (2005). Some figures of the larva of $N$. johnstoni, labelled as Neolimnochares sp., were used in a key published by Smith, Cook and Smith (2001). Because the larva of the type species of the genus, $N$. placophora (Lundblad 1937), is still unknown, the attribution of $N$. johnstoni to the genus Neolimnochares remains tentative in the light of the diversity of larval morphology discovered in Neolimnocharinae. Resolution of this taxonomic problem will only be possible when the larval stage of $N$. placophora becomes known.

\section{Neolimnochares sp. A}

Limnochares australica (not Lundblad, 1941a): Martin and Smit 2002: 410 (larva; erroneous attribution).

Remarks

Martin and Smit (2002) described a larval stage collected on Tenagogerris pallidus Andersen and Weir, 1997 (Hemiptera; Gerridae) in Western Australia, which they assumed to be that of 
Limnochares australica. However, they noticed differences between this larva and those of other Limnochares species, in particular the presence, in addition to the empodium, of a modified claw with a proximal extension on legs I-III. Although Martin and Smit (2002) made reference to these two structures as a pair of differently shaped claws, we follow here the interpretation most frequently adopted in the literature - that it is one of the lateral claws that is lost, rather than the empodium (Smith et al. 2010 and bibliography therein). Evidently, when preparing their publication, Martin and Smit (2002) were not aware of the first morphological data on a Neolimnochares larva given in the key of Smith, Cook and Smith (2001). The description of the Australian larva provides the details required for a reinterpretation of its taxonomic status, namely the presence of a modified claw, the broad size of the anal sclerite in combination with the absence of modified setae on coxae I-III. These indicate a close relationship to N. johnstoni, although they differ in the location of setae $1 a$ on coxa I (lateral position in $N$. sp. A, versus medial and close to seta $1 b$ in $N$. johnstoni). The identification of the larva as Limnochares australica was solely based on the presence of adults of the latter at the same location. However, the sympatric occurrence of two or more species of the same or closely related genera of Parasitengona is quite frequent (Wohltmann 2001), so we consider the proposed correlation to be incorrect. This Neolimnochares larva might conceivably be that of $N$. kakadu Harvey, 1990, the only species of Neolimnochares hitherto described from Australia and currently only known from postlarval instars. The situation will only become clear when rearing or molecular analyses have been carried out. Because of the lack of data in the published description and the poor state of embedded specimens, the larva is provisionally termed Neolimnochares sp. A.

\section{Archaeveliacola gen. $\mathbf{n}$.}

Type species

Archaeveliacola papuanus sp. n.

\section{Diagnosis}

Larva. Neolimnocharinae with setae $1 a-b$ of coxa I ctenidial, with several posteriorly directed tines; coxae II-III each with 1 smooth seta, without modified setae. Gnathosomal shield small, not laterally extended.

Postlarval instars. Unknown. 


\section{Etymology}

A combination of the Greek prefix archaios, meaning ancient, and the genus name Veliacola. Gender masculine.

\section{Distribution}

Indonesia (Papua Barat), Australia.

\section{Archaeveliacola papuanus sp. $\mathbf{n}$.}

\section{Type locality}

Indonesia, Papua Barat, above Kebar, forest creek, near -0.785S, 133.071E, $721 \mathrm{~m}$ above sea level.

\section{Type material}

Holotype. Larva, Indonesia, Papua Barat, locality (Loc.) 060, above Kebar, forest creek, near $-0.785 \mathrm{~S}, 133.071 \mathrm{E}, 721 \mathrm{~m}$ above sea level, 7.V.2015, leg. UNIPA team, detached from Rhagovelia sp., + , frons, slide mounted (MZB).

Paratypes. 15 larvae, same label data as holotype, detached from their hosts (Rhagovelia sp. $\widehat{\jmath} \widehat{\delta}$ and 9 우), slide mounted; 37 larvae, same label data as holotype, attached to Rhagovelia sp. $\widehat{\delta} \hat{\sigma}$ and $q$ 우, in ethanol; 3 larvae, same label data as holotype, detached from Rhagovelia sp. đ̃, frons, slide mounted; 3 larvae, Indonesia, Papua Barat, Loc. 043, Sausapor-Fef, -0.599S, 131.963E, $50 \mathrm{~m}$ above sea level, 30.IX.2014, leg. UNIPA team, detached from 'Rhagovelia bacanensis sp. A', frons, $q$ (2 larvae), ô (1 larva) (MZB).

\section{Additional material}

6 detached larvae and 4 larvae in situ on their hosts, prepared for SEM investigation, Indonesia, Papua Barat, Loc. 043, Sausapor-Fef, -0.599S, 131.963E, $50 \mathrm{~m}$ above sea level, 30.IX.2014, leg. UNIPA team.

\section{Description}

Larva. Metric data given in Table 2. Colour in life unknown. Idiosoma length $150 \mu \mathrm{m}$ (unengorged) to $340 \mu \mathrm{m}$ (engorged); dorsum (Figures 3a, f) with scutum subrectangular, setae setulose. Paired eyes located on oval sclerites (length/width $20 / 10 \mu \mathrm{m}$ ) at level of setae $P M$. Each pair composed of an anterior (diameter $9 \mu \mathrm{m}$ ) and posterior (diameter $7 \mu \mathrm{m})$ lens. Rest of dorsum with smooth, plicate cuticle. Dorsal setae $(30-45 \mu \mathrm{m})$ barbed, arranged in rows and 
situated on platelets (length/width $10 / 5 \mu \mathrm{m}$ ); $\mathrm{C}$ row with $\mathrm{c}_{1-2}$; D row with $\mathrm{d}_{1-2}$; E row with $\mathrm{e}_{1-}$ 2, F row with $\mathrm{f}_{1-2}, \mathrm{H}$ row with $\mathrm{h}_{1-2}$; setae $\mathrm{h}_{1}$ located on a common posterior plate (length/width 30/35 $\mu \mathrm{m})$.

Venter (Figures 3b, g) dominated by large coxal plates of legs I-III. Coxa I with anterior part bent ventrally, carrying 2 ctenidial setae $1 a, 1 b$ (each $12 \mu \mathrm{m}$ long, $7 \mu \mathrm{m}$ wide, with about $12-$ 14 tines) (Figure 3h); laterally with a dorsal extension of coxa covering base of trochanter I. Coxa II with smooth seta $2 a(30 \mu \mathrm{m})$; laterally with an extension covering base of trochanter II; 2 Claparède's organs ( $c l p)$ at anterior margin. Coxa III directed posterolaterad, with smooth seta $3 a(27 \mu \mathrm{m})$, anterolateral margin of coxa III extended to cover base of trochanter III. Anal pore located between coxae III, surrounded by an undivided anal sclerite (length/ width $10 / 10 \mu \mathrm{m})$, no setae on anal sclerite. Posterior to anal sclerite is a pair of barbed setae ps $(20-22 \mu \mathrm{m})$.

Gnathosoma (Figure 3c) with ics (Figure 3i) small (length/width 16-20/36-42 $\mu \mathrm{m}$ ). Anteriorly with a pair of smooth setae $c s(18-22 \mu \mathrm{m})$, located dorsally on gnathosomal shield. Smooth setae $b s(3-5 \mu \mathrm{m})$ located ventrally, midway between mouth opening and palp

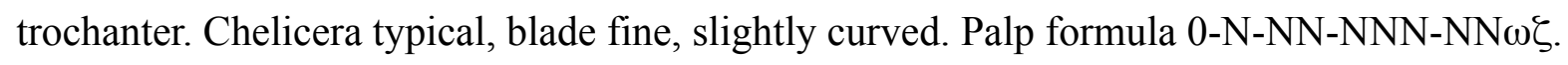
Femur large, with 1 setulose seta $(40 \mu \mathrm{m})$ in dorsolateral position; genu with 2 smaller, setulose setae $(35 \mu \mathrm{m})$; tibia with 2 longer $(15 \mu \mathrm{m})$ and 1 smaller $(7 \mu \mathrm{m})$ smooth setae close to base of odontus. Odontus $(15 \mu \mathrm{m})$ divided almost to base; tarsus with 3 pit-like setae (2 $\mu \mathrm{m}), 1$ small eupathidium $(4 \mu \mathrm{m})$ and 1 solenidion $\omega(6 \mu \mathrm{m})$ (Figure $3 \mathrm{k})$.

Leg chaetotaxy as in Table 3 and Figures 3d-e. Each trochanter with 1 large, setulose seta; telofemora of legs I-III with each 1 trichobothrium in dorsal position; setae $\kappa$ on genua I and II prominent. Tarsi I-III, in addition to the normal empodium, each with a modified claw with a broadened base as described for N. johnstoni (Figure 31).

Postlarval instars. Unknown.

Etymology

Named after the provinces of Indonesia where the type locality is situated. The name is a case sensitive adjective.

\section{Distribution}

Indonesia, Papua Barat. 


\section{Host}

Rhagovelia sp. (Hemiptera: Veliidae). Larvae generally found attached to the frons between the antennae (Figures 1e-f).

\section{Archaeveliacola smiti sp. n.}

\section{Type locality}

Australia, Queensland, Tully Gorge National Park, Creek north of Tully River, $17^{\circ} 46.195 \mathrm{~S}$, $143^{\circ} 39.461 \mathrm{E}, 134 \mathrm{~m}$ above sea level.

\section{Type material}

Holotype. Larva, Australia, Queensland, Tully Gorge National Park, Creek north of Tully River, $17^{\circ} 46.195 \mathrm{~S}, 143^{\circ} 39.461 \mathrm{E}, 134 \mathrm{~m}$ above sea level, 4.XI.2014 leg. Smit, slide mounted (QMS 110161); specimen mounted upside down on slide, which makes some of the dorsal structures difficult to examine at higher magnifications.

\section{Description}

Larva. Metric data given in Table 2. Colour in life unknown. All sclerotised parts finely punctate, with internal fine longitudinal striation. Idiosoma length in engorged larvae about 300-550 $\mu \mathrm{m}$; dorsum (Figure 4a) with scutum approximately rectangular; setae setulose. Paired eyes located on oval sclerites (length/width $26 / 16 \mu \mathrm{m}$ ) at level of setae $P M$. Each pair composed of anterior (diameter $10 \mu \mathrm{m})$ and posterior (diameter $9 \mu \mathrm{m})$ lens. Rest of dorsum with smooth, plicate cuticle. Dorsal setae $(40-60 \mu \mathrm{m})$ barbed, arranged in rows and situated on platelets (length/width $20 / 12 \mu \mathrm{m}$ ); $\mathrm{C}$ row with $\mathrm{c}_{1-2}$; D row with $\mathrm{d}_{1-2}$; $\mathrm{E}$ row with $\mathrm{e}_{1-2}, \mathrm{~F}$ row with $\mathrm{f}_{1-2}, \mathrm{H}$ row with $\mathrm{h}_{1-2}$; setae $\mathrm{h}_{1}$ located on a common posterior plate (length/width 14/30 $\mu \mathrm{m})$.

Venter (Figure 4b) dominated by large coxal plates of legs I-III. Coxa I with anterior part bent ventrally, carrying 2 ctenidial setae ( $1 a, 1 b$; each with length/width: $10 / 15 \mu \mathrm{m}$, with about 8 tines); laterally, a dorsal extension of the coxa covering proximal part of trochanter I. Coxa II with smooth seta $2 a(45 \mu \mathrm{m})$; an extension of the coxa covering proximal part of trochanter II laterodorsally; 2 Claparède's organs $(\mathrm{clp})$ at anterior margin. Coxa III directed posterolaterad, with smooth seta $3 a(25 \mu \mathrm{m})$. Anal pore located between coxae III, surrounded by an undivided anal sclerite (length/width $16 / 12 \mu \mathrm{m})$ carrying 2 smooth setae $(20 \mu \mathrm{m})$. Posterior to anal sclerite is a pair of barbed setae $p s(32 \mu \mathrm{m})$. 
Gnathosoma (Figure 4c) with ics present (length/width $80 / 50 \mu \mathrm{m}$ ), but difficult to observe due to orientation of mounted larva. Anteriorly with a pair of smooth setae cs $(18 \mu \mathrm{m})$. Smooth setae $b s(10 \mu \mathrm{m})$ located midway between mouth opening and palp trochanter. Chelicera

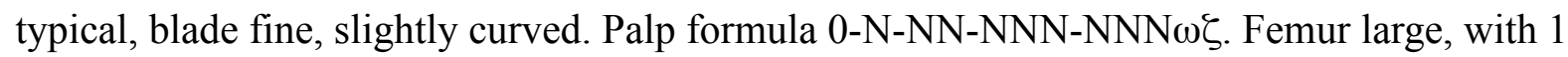
setulose seta $(35 \mu \mathrm{m})$ in dorsolateral position; genu with 2 smaller, setulose setae $(20-30 \mu \mathrm{m})$; tibia with 2 longer $(30 \mu \mathrm{m})$ and 1 smaller $(10 \mu \mathrm{m})$ smooth setae close to base of odontus. Odontus $(18 \mu \mathrm{m})$ divided for almost all its length; tarsus with 3 smooth setae $(6 \mu \mathrm{m}), 1$ small eupathidium $(2 \mu \mathrm{m})$ and 1 solenidion $\omega(4 \mu \mathrm{m})$.

Leg chaetotaxy as in Table 3 and Figures 4d-e. Each trochanter with 1 large, setulose seta; telofemora of legs I-III each with 1 trichobothrium in dorsal position; Setae $\kappa$ on genua I and II prominent. Legs I-III each with empodium and claw similar in shape, both with broadened bases and modified as described for $N$. johnstoni.

Postlarval instars. Unknown.

Etymology

Named after the collector, Harry Smit (Alkmaar). The name is a noun not in apposition.

Host

Rhagovelia australica Kirkaldy, 1908 (Hemiptera: Veliidae); larvae attached laterally to thorax.

\section{Distribution}

Australia, Queensland, only known from the type locality.

Remarks

Archaeveliacola smiti differs from the other species of the genus in having a claw that is similar in shape to the empodium on legs I-III (i.e., lacking the proximal enlargement of the claw seen on legs of $A$. papuanus).

\section{Veliacola gen. $\mathbf{n}$.}

Type species

Veliacola mirificus sp. n. 


\section{Diagnosis}

Larva. Neolimnocharinae with laterally enlarged gnathosomal shield; setae $1 a-b$ on Coxa I palmate, with several posteriorly directed tines; coxa II-III, in addition to the single smooth seta, with a transverse taeniform seta. Setae $h_{1}$ on a common sclerite.

Postlarval instars. Unknown.

Etymology

Combining Velia, used as a stem in generic names of the host family (Veliidae), with the Latin suffix -cola, meaning living on. Gender masculine.

\section{Distribution}

Madagascar, Caribbean (Dominican Republic).

\section{Veliacola mirificus sp. $\mathbf{n}$.}

Type locality

Madagascar, Antsiranana, Montagne d'Ambre (Joffreville), Cascade sacrée, pool, $1040 \mathrm{~m}$ above sea level.

Type material

Holotype. Larva, Madagascar, Antsiranana, Montagne d'Ambre (Joffreville), Cascade sacrée, pool, $1040 \mathrm{~m}$ above sea level, 23.III.2011, leg. Gerecke (MD 181), slide mounted (MHNH). Paratype. Larva, with same label data as holotype, mounted for SEM investigation (MNHN).

\section{Description}

Larva. Metric data given in Table 2. Colour in life unknown. All sclerotised parts finely punctate, with an underlying fine longitudinal striation. Idiosoma length in slightly engorged larvae about $280 \mu \mathrm{m}$; dorsum (Figures 5a, 5f) with scutum approximately rectangular, without trichobothria; setae setulose. Paired eyes located on oval sclerites (length/width 22/10 $\mu \mathrm{m}$ ) at level of setae $P M$. Each pair composed of anterior (diameter 8-9 $\mu \mathrm{m}$ ) and posterior (diameter 7-8 $\mu \mathrm{m})$ lens. The remaining part of dorsum with smooth, plicate cuticle. Dorsal setae (35-50 $\mu \mathrm{m})$ barbed, arranged in rows and situated on platelets (length/width 15/10 $\mu \mathrm{m}$ ); C row with $\mathrm{c}_{1-2}$; D row with $\mathrm{d}_{1-2}$; E row with $\mathrm{e}_{1-2}$, F row with $\mathrm{f}_{1-2}, \mathrm{H}$ row with $\mathrm{h}_{1-2}$; setae $\mathrm{h}_{1}$ located on a common posterior plate (length/width $25 / 30 \mu \mathrm{m}$ ). 
Venter (Figures 5g, 5o, 10a) dominated by large coxal plates of legs I-III. Coxa I anterior margin bent ventrally, carrying 2 palmate setae $(1 a, 1 b$; each $30 \mu \mathrm{m})$, each with about 8 tines; laterally, a dorsal extension of coxa covers proximal part of trochanter I. Coxa II with a smooth seta $2 a(30 \mu \mathrm{m})$ and, about halfway along its length, a transverse taeniform seta $(2 b)$ nearly reaching across the width of the coxa; a laterodorsal extension of the coxa covering proximal part of trochanter II; 2 Claparède's organs ( $c l p)$ at anterior margin. Coxa III directed posterolaterad, with smooth seta $3 a(25 \mu \mathrm{m})$ and about halfway its length a taeniform seta $(3 b)$ as long as that on II. Anal pore located between coxae III, surrounded by an undivided anal sclerite (length/width $16 / 11 \mu \mathrm{m})$ carrying 2 smooth setae $(12-15 \mu \mathrm{m})$. Posterior to anal sclerite 2 barbed setae ps $(30 \mu \mathrm{m})$.

Gnathosoma (Figures 5b, 5k) with dorsal part almost completely covered by ics (length/width $80 / 100 \mu \mathrm{m}$ ), which leads posteriorly to the dorsal region of the basal segment of the chelicera. At its anterior part, the shield carries paired, smooth setae $c s(20 \mu \mathrm{m})$ dorsally. Ventral part of gnathosoma with smooth setae $b s(15 \mu \mathrm{m})$. Chelicera typical, cheliceral blade fine, slightly

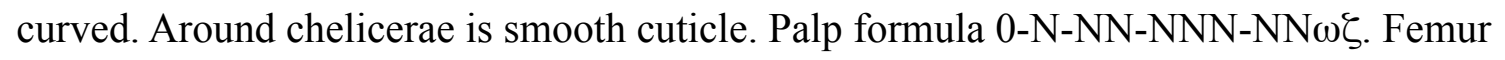
large, carrying a prominent setulose seta $(80 \mu \mathrm{m})$ in dorsolateral position; genu with 2 smaller, smooth setae $(12-15 \mu \mathrm{m})$; tibia with 3 small, smooth setae $(3,6$ and $10 \mu \mathrm{m})$, odontus $(18 \mu \mathrm{m})$ bifid; tarsus with 1 smooth seta $(6 \mu \mathrm{m}), 1$ small spine, 1 small eupathidium $(2 \mu \mathrm{m})$ and 1 solenidion $\omega(4 \mu \mathrm{m})$.

Leg chaetotaxy as in Table 3 and Figures 5c-e, 51-n. Each trochanter with 1, large, setulose seta; telofemora of leg I-III each with 1 trichobothrium in dorsal position; microsetae $\kappa$ on genua I and II prominent. Tarsi I-III each with thin, elongate, empodium and 1 claw. Claw of legs I and II modified with a broadened base as described for N. johnstoni; claw of leg III elongate, without broadened base.

Postlarval instars. Unknown.

Etymology

Latin: mirificus, meaning admirable. The name is a case sensitive adjective.

Host

Rhagovelia sp. (Hemiptera: Veliidae). Larvae attached to dorsal sclerotised areas of femora (Figures 1d, 5h-j). 


\section{Distribution}

Only known from a stream on the Montagne d'Ambre (N. Madagascar).

\section{Remarks}

The palp tarsus is difficult to observe in both specimens, with the shape of odontus and the small setae on palp tibia being obscured.

For characters supporting the homologies of the ctenidial and taeniform setae with normal setae $1 a, b, 2 b$ and $3 b$ respectively, see discussion below.

A further, currently undescribed species (Veliacola sp. A in Table 1) of this genus is represented by five larvae parasitic on Rhagovelia collaris (Burmeister, 1835), collected in the Dominican Republic ('La Vega Province, El Rio (24 km NE), 12 November 1984, leg. P. and P. Spangler and R. Faitoute', USNM). These larvae are fragmented and unsuitable for a formal description, but their observable characters (presence of trichobothria on telofemora IIII, paired Claparède's organs near coxa II, setae $1 a$ and $1 b$ palmate, each with $6-7$ tines, and coxa II and III with a transverse taeniform seta), indicate that they belong to Veliacola. They differ from $V$. mirificus in the presence of a proximally broadened claw on leg III, similar to those of legs I-II (as opposed to elongate claws without proximal enlargement on leg III in $V$. mirificus).

\section{Isoveliacola gen. $\mathbf{n}$.}

Type species

Isoveliacola costaricensis $\mathrm{sp} . \mathrm{n}$.

\section{Diagnosis}

Larva. Neolimnocharinae with bifid, distally elongate palp-tarsus. Paired Claparède's organs at anterior margins of each coxa II. Setae $1 a, 1 b$, ctenidial, with multiple finger-like lobes. Coxae II-III each with 1 smooth setiform seta plus 1 ctenidial seta with multiple finger-like lobes. All coxae with dorsal extensions which cover leg insertions. Setae $\mathrm{h}_{1}$, when present, on a common sclerite.

Postlarval instars. Unknown.

\section{Etymology}


Combination of the Greek suffix isos (equal) with the genus name Veliacola. Gender masculine.

\section{Distribution}

Central America (Costa Rica), Indonesia (Borneo).

\section{Isoveliacola borneoensis sp. $\mathbf{n}$.}

\section{Type locality}

Indonesia, Borneo, Kalimantan, site 7: Niatu River, tributary of Kahagan River, small stream.

\section{Type material}

Holotype. Larva, Indonesia, Borneo, Kalimantan, site 7: Niatu River, tributary of Kahagan River, small stream, 20.VII.2004, leg. P. Mazzoldi, on Rhagovelia sp. §̊, detached from abdominal dorsal intersegment, slide mounted (NHMW).

Paratype. Larva, same label data and host as holotype, detached from right side of mesothorax, slide mounted (NHMW).

\section{Additional material}

Larva, Indonesia, Borneo, Kalimantan, site 3: Bulus River and mouth of Jepang River, 19.VII. 2004, leg. P. Mazzoldi, on Rhagovelia sp. +, detached from lateral abdomen, mounted for SEM-investigation.

\section{Description}

Larva. Metric data given in Table 2. Colour in life unknown. Idiosoma length in slightly engorged larvae 220-230 $\mu \mathrm{m}$, dorsum (Figure 6a) with scutum roughly pentagonal, surface with longitudinal striae. Setae $A M, A L, P M$ and $P L$ setulose. Paired eyes located on oval sclerites (length/width 16/10-12 $\mu \mathrm{m}$ ) at the level of setae $P M$. Anterior lens diameter $6 \mu \mathrm{m}$, posterior lens diameter 5-6 $\mu \mathrm{m}$. Rest of dorsum with smooth, linearly folded cuticle. Dorsal setae $(35-55 \mu \mathrm{m})$ setulose, arranged in rows and situated on platelets (length/width $10 / 5 \mu \mathrm{m})$; C row with $\mathrm{c}_{1-2}$; D row with $\mathrm{d}_{1-2}$; E row with $\mathrm{e}_{1-2}, \mathrm{~F}$ row with $\mathrm{f}_{1-2}, \mathrm{H}$ row with only 1 pair of setae on separate sclerites.

Venter (Figures 6b, 10b) dominated by large coxal plates of legs I-III. Coxa I carrying 2 ctenidial setae $(1 a, 1 b)$, each with about 6 tines. Coxa II with smooth seta $2 a(20 \mu \mathrm{m})$ and 
ctenidial seta (2b) bearing about 12 tines. Two Claparède's organs ( $c l p)$ at anterior margin of each coxa II. Coxa III directed posterolaterally, with smooth seta $3 a(25 \mu \mathrm{m})$ and ctenidial seta $(3 b)$ bearing about 12 tines. Each coxa with dorsal extension covering the proximal part of trochanter. Anal pore between coxae III surrounded by an undivided anal sclerite (length/ width $12-14 / 12 \mu \mathrm{m})$ bearing 2 smooth setae $(18-20 \mu \mathrm{m})$. Two barbed setae $p s(25 \mu \mathrm{m})$ behind anal sclerite.

Gnathosoma (Figures 6c-d) with ics (length/width 24-26/46-52 $\mu \mathrm{m}$ ) carrying paired, setulate setae $c s(15-21 \mu \mathrm{m})$ anterodorsally. Ventral part of gnathosoma with smooth setae $b s(7 \mu \mathrm{m})$. Chelicera typical, blade fine, slightly curved. Chelicerae surrounded by smooth cuticle. Palp formula $0-\mathrm{N}-\mathrm{NN}-\mathrm{NNN}-\mathrm{NNN} \omega \zeta$. Palp femur large, carrying a setulose seta $(25 \mu \mathrm{m})$ in dorsolateral position, palp genu with 2 smaller, setulose setae (26-30 and 30-35 $\mu \mathrm{m})$. Palp tibia with 2 setulose setae $(25 \mu \mathrm{m})$ plus 1 smooth spine-like seta $(8 \mu \mathrm{m})$ close to base of odontus. Odontus $(20 \mu \mathrm{m})$ bifid with elongate tips almost parallel. Palp tarsus with 2 smooth setae $(10 \mu \mathrm{m}), 1$ small spine, 1 small eupathidium $(2 \mu \mathrm{m})$ and 1 solenidion $\omega(5 \mu \mathrm{m})$.

Leg chaetotaxy as in Table 3. Telofemur of each leg I-III with 1 trichobothrium in dorsal position. Setae $\kappa$ on genua I and II prominent. Legs I-III each with elongate, thin empodium and a modified claw with broadened base as described for $N$. johnstoni.

Postlarval instars. Unknown.

\section{Distribution}

Borneo (Indonesia), only known from two neighbouring streams in Kalimantan.

\section{Etymology}

Named after the island from which the types were collected. The name is a case sensitive adjective.

\section{Host}

Rhagovelia sp. (Hemiptera: Veliidae). Found attached to one + (side of abdomen) and two $\widehat{\partial} \widehat{\partial}$ (dorsal intersegment of abdomen and right mesothorax).

\section{Remarks}

See discussion under I. costaricensis concerning the differences between them. 


\section{Isoveliacola costaricensis sp. $\mathbf{n}$.}

\section{Type locality}

Costa Rica, Puntarenas, Esquinas rain forest, site 2, Quebrada Negra (area of the biological station, agricultural land), $70 \mathrm{~m}$ above sea level.

\section{Type material}

Holotype. Larva, Costa Rica, Puntarenas, Esquinas rain forest, site 2, Quebrada Negra (area of the biological station, agricultural land), $70 \mathrm{~m}$ above sea level, 11.II.1995, leg. P. Sehnal, detached from Rhagovelia sp. (attachment site unknown), slide mounted (NHMW).

Paratypes. 5 larvae with same label data and host as holotype, slide mounted, 1 detached, attachment site unknown, 4 on 9 prosternum. 4 larvae, same area as holotype, site 3, Quebrada Negra (area of Lodge, secondary forest), $80 \mathrm{~m}$ above sea level, 11.II.1995, on $R$. sp. (2 larvae on $\uparrow, 2$ larvae on $\overbrace{}^{\Uparrow}$ ), slide mounted. 1 larva, same area as holotype, site 5, Quebrada Gamba (agricultural area), $70 \mathrm{~m}$ above sea level, 14.II.1995, on R. sp. O̊, slide mounted. 5 larvae, same area as holotype, site 19, Rio Bonito (transitional zone between primary forest, secondary forest and agricultural area), $80 \mathrm{~m}$ above sea level, 6.III.1995, on $R$. sp., slide mounted; 18 larvae detached from antennal base, or leg I-III femora of their hosts, in ethanol, same area as holotype, site 6, Quebrada Negra (agricultural area), $120 \mathrm{~m}$ above sea level, 15.II.1995: on $R$. crassipes Champion, 1898 (3 larvae on 우; 1 larva on $§$ ); on $R$. femoralis Champion, 1898 (2 larvae on $\widehat{\partial} \widehat{\partial}, 1$ larva on + ); on R. uncinata Champion, 1898 (1 larva on ふ); on R. sp. n. hirtipes-group (5 larvae on $\widehat{\partial}, 1$ larva on $\Phi$; 4 larvae on $\widehat{\partial}, \mathrm{MNHN}$ ) (all material except for the specified 4 larvae NHMW).

\section{Additional material}

3 larvae, with same label data as holotype, detached from Rhagovelia femoralis, prepared for SEM investigation.

\section{Description}

Larva. Metric data given in Table 2. Colour in life unknown. Idiosoma length 110 (unfed) to $327 \mu \mathrm{m}$ (engorged); dorsum (Figures $7 \mathrm{a}-\mathrm{b}$ ) with scutum roughly pentagonal, surface with longitudinal striae. Setae $A M, A L, P M$ and $P L$ setulose. Paired eyes located on oval sclerites (length/width 16/10-12 $\mu \mathrm{m}$ ) at level of setae $P M$. Anterior lens diameter $6 \mu \mathrm{m}$, posterior lens diameter 5-6 $\mu \mathrm{m}$. Rest of dorsum with smooth, linearly folded cuticle. Dorsal setae (20-38 
$\mu \mathrm{m})$ barbed, arranged in rows and situated on platelets (length/width $10 / 5 \mu \mathrm{m}$ ); $\mathrm{C}$ row with $\mathrm{c}_{1-}$ 2; D row with $\mathrm{d}_{1-2}$; E row with $\mathrm{e}_{1-2}, \mathrm{~F}$ row with $\mathrm{f}_{1-2}, \mathrm{H}$ row with $\mathrm{h}_{1-2}$; setae $\mathrm{h}_{1}$ setae located on a common posterior plate (length/width $15 / 15 \mu \mathrm{m}$ ).

Venter (Figures 7c, 10c) dominated by large coxal plates of legs I-III. Coxa I carrying 2 ctenidial setae $(1 a, 1 b)$, each with 6-9 tines. Coxa II with smooth seta $2 a(40 \mu \mathrm{m})$ and ctenidial seta $(2 b)$ bearing about 11-16 tines. Two Claparède's organs $(c l p)$ at anterior margin of each coxa II. Coxa III directed posterolaterally, with smooth seta $3 a(40 \mu \mathrm{m})$ and ctenidial seta $(3 b)$ bearing about 10-13 tines. Each coxa with dorsal extension covering proximal part of trochanter. Anal pore between coxae III surrounded by an undivided anal sclerite (length/ width $12 / 10 \mu \mathrm{m})$ bearing 2 smooth setae $(25-30 \mu \mathrm{m})$; one specimen with only 1 seta on anal sclerite. Two barbed setae ps $(25-30 \mu \mathrm{m})$ behind anal sclerite.

Gnathosoma (Figure 7d) in anterior half dorsally covered by ics (length/width 18/26 $\mu \mathrm{m}$ ) which anterodorsally carries paired, setulose setae $c s(15-17 \mu \mathrm{m})$. Ventral part of gnathosoma with smooth setae $b s(7 \mu \mathrm{m})$. Chelicera typical, blade fine, slightly curved. Chelicera surrounded by smooth cuticle that serves to seal insertion of chelicerae into host cuticle. Palp formula $0-N-N N-N N N-N N N \omega \zeta$. Palp femur large, carrying a setulose seta $(25-30 \mu \mathrm{m})$ in dorsolateral position, palp genu with 2 smaller, setulose setae (15-16 and 20-25 $\mu \mathrm{m})$. Palp tibia with 2 setulose setae $(14-20 \mu \mathrm{m})$ plus 1 smooth spine-like seta $(5-7 \mu \mathrm{m})$ close to base of odontus. Odontus $(10-15 \mu \mathrm{m})$ bifid with elongate tips almost parallel. Palp tarsus with 2 smooth setae $(10 \mu \mathrm{m}), 1$ small spine, 1 small eupathidium $(2 \mu \mathrm{m})$ and 1 solenidion $\omega(5 \mu \mathrm{m})$. Leg chaetotaxy as in Table 3 and Figures 7e-f. Telofemur of each leg I-III with 1 trichobothrium in dorsal position. Setae $\kappa$ on genua I and II prominent. Legs I-III each with elongate, thin empodium flanked by a claw with broadened base and retractable spine in its distal half.

Postlarval instars. Unknown.

\section{Distribution}

Costa Rica; only known from streams in the Esquinas rain forest (Puntarenas).

\section{Etymology}

Named after Costa Rica, the country in which the types were collected. The name is a case sensitive adjective. 
Rhagovelia femoralis, $R$. crassipes, $R$. uncinata, $R$. undescribed sp. of the hirtipes-group, and $R$. sp.; preferred attachment sites: membranous areas on frontal and ventral surface of head, in particular near antennal insertions (Figure 6e); anterior margin of prosternum; femora, rarely coxae, tibiae or trochanters of all legs. On some hosts, exuviae of larvae were found.

\section{Remarks}

The larva of Isoveliacola costaricensis differs from that of I. borneoensis by its smaller size (e.g., leg tarsi $<50 \mu \mathrm{m}$, palp femur $<30 \mu \mathrm{m}$ ). The presence of $\mathrm{h}_{1}$ setae located on a common sclerite may constitute another differentiating character, but this region was difficult to observe in all three specimens of I. borneoensis and thus the sclerite and setae might have been overlooked.

\section{Armaveliacola gen. $\mathbf{n}$.}

Type species

Armaveliacola rhagoveliae sp. $\mathrm{n}$.

\section{Diagnosis}

Larva. Neolimnocharinae with laterally enlarged gnathosomal shield and scutum, the latter carrying 8 normal setae $(A M, A L, P M, P L)$; a scutellum with 2 setae $\mathrm{c}_{1}, 3$ pairs of lateral platelets carrying setae $\mathrm{c}_{2-3}$ and $\mathrm{d}_{2}$, adjacent to scutum and scutellum, and a small posterodorsal plate bearing setae $\mathrm{h}_{1}$. Coxae of legs I-III extended dorsolaterally to form sleeves that completely cover trochanters. Coxae I with setae $1 b$ at anterior margin, extremely enlarged, club-shaped, with a lamellar tip; seta $1 a$ large, ctenidial, with 28-38 finger-like tines arranged in a transverse line; coxae II-III each with simple setae $2 a$ and $3 a$ plus a ctenidial seta $(2 b, 3 b)$. Two pairs of Claparède's organs, each at anterior margin of coxae II and III. Gnathosoma completely covered dorsally by a shield formed by dorsolateral extensions of the palp coxae; laterally, palp femur fills gap between lateral extensions of coxae I and posterolateral margins of gnathosomal shield.

Postlarval instars. Unknown.

Etymology

Genus name is a combination of the Latin arma (armour) and Veliacola. Gender masculine. 


\section{Distribution}

Madagascar and continental Africa.

\section{Remarks}

In unfed larvae, the sclerites almost completely cover the soft body-even the eyes and Claparède's organs are hidden under overlapping sclerites. Some of these sclerites (e.g., the gnathosomal shield, ics) are rather thin and might be overlooked in cleared larvae. When it starts to engorge, the larva swells and the soft cuticle becomes visible between the sclerites. Armaveliacola differs from other Neolimnocharinae in (1) $\mathrm{c}_{1}$ platelets fused (versus separate) (2) dorsal part of chelicerae completely covered by the posterior extension of ics (versus ics not covering the posterior part of the cheliceral bases); (3) trochantera I-III completely hidden in cavities formed by the coxae (versus exposed or only partly covered by lateral and dorsal extension of coxae); (4) seta $1 b$ club-shaped, with lamellar surface (versus setiform or ctenidial, with finger-like tines); (5) setae $1 a, 2 a$ and $3 a$ transverse, ctenidial, with $>25$ finger-like tines (versus $<20$ tines or none); (6) paired Claparède's organs on coxae II and III (versus restricted to coxae II) and (7) anal plate more elongate.

\section{Armaveliacola major sp. $\mathbf{n}$.}

\section{Type locality}

Madagascar, Diego Suarez, no precise locality.

\section{Type series}

Holotype. Larva, Madagascar, Diego Suarez, no precise locality, 1893, leg. C.A. Alluaud, detached from Rhagovelia sp., slide mounted (MNHN).

Paratypes. 1 larval exoskeleton, same label data as holotype, extracted for DNA-analysis, slide-mounted. 1 larva, same label data as holotype, undissected in pure ethanol. 7 larvae, slide-mounted together with paratype larva of $A$. rhagoveliae (slide 19 C 12, 'Diego Suarez, sur Velia' - from collection of Trouessart, partially dried out, larvae compressed) (MNHN).

\section{Additional material}

2 larvae, same label data as holotype, prepared for SEM investigation. Larva, Madagascar, Andrambovato, rain forest, site 153, 6.VIII.1958, leg. F. Starmühlner, detached from Rhagovelia adrienneaebrasili Poisson, 1945 ô, left abdominal segment I, slide mounted 
(NHMW). Starmühlner (1962) gives two collecting sites with that date (both without numbers or mention of Veliidae), but only the following was located in rain forest: 'Falaise près d'Andrambovato (station de la ligne de chemin de fer de Fianarantsoa à Manakara, 15 kilomètres à l'est de la station forestière d'Ampomaharena), ruisseau de Beromazava [...] dans la forêt vièrge $[\ldots]$ '.

\section{Description}

Larva. Metric data given in Table 2. Colour in life unknown. Idiosoma (Figures. 8a, 9b) length $300 \mu \mathrm{m}$ (partly engorged), shape and setation of sclerites as described for the genus (see above). Eye sclerites length/width 30-31/17-18 $\mu \mathrm{m}$, anterior lens diameter 10, posterior 8 $\mu \mathrm{m}$. Length $\mathrm{c}_{1} 80-100 \mu \mathrm{m}, \mathrm{c}_{2}, \mathrm{~d}_{1-2}, 90-125 \mu \mathrm{m}$, dorsal setae $35-50 \mu \mathrm{m}$, diameter of setal platelets $10-13 \mu \mathrm{m}$, diameter of plate bearing $\mathrm{h}_{1} 20 \mu \mathrm{m}$.

Venter (Figure 10d) dominated by large coxal plates of legs I-III. Coxa I with clavate seta (1b) 60-75 $\mu \mathrm{m}$ long (Figures 8b, 8e) and ctenidial seta (1a) straight or only weakly curved anteriorly (Figure 8b-c), with about 30 finger-like tines. At high magnification (Figure 8d), these tines appear dorsoventrally flattened in their proximal part, with a characteristic, distally-directed triangular impression, in their distal part rounded or laterally compressed, showing a very fine longitudinal lineation. Coxa II with setiform seta $2 a(40-45 \mu \mathrm{m})$, ctenidial seta $(2 b)$ straight or weakly curved, with about 35 tines, coxa III with setiform seta $3 a(80 \mu \mathrm{m})$, ctenidial seta $(3 b)$ strongly curved, with 35-39 tines. Anal sclerite length/width 140/40 $\mu \mathrm{m}$, anal setae 45-60 $\mu \mathrm{m}$, setae ps $80 \mu \mathrm{m}$.

Gnathosoma (Figure 8b) with ics, length/width 120/200 $\mu \mathrm{m}$, setae cs $23 \mu \mathrm{m}$, spine-like setae bs $5 \mu \mathrm{m}$. Palp femur seta length 50-60 $\mu \mathrm{m}$, genu setae length $28-30 \mu \mathrm{m}$, tibia with 2 small setae $(5-10 \mu \mathrm{m})$ and 1 longer seta $(30 \mu \mathrm{m})$; odontus width $20-27 \mu \mathrm{m}$; tarsus eupathidium 6 $\mu \mathrm{m}$, solenidion $(\omega) 6 \mu \mathrm{m}, 3$ smooth setae $(4 \mu \mathrm{m})$.

Leg chaetotaxy as in Table 3 . All legs with trochanter small, completely hidden in a cavity formed by laterodorsal extensions of coxae; basifemur conical, bent upwards shortly after base and widening distally; telofemur with 1 trichobothrium in dorsal position; legs I-III each with thin, elongate empodium and modified claw with a broadened base as described for $N$. johnstoni.

Postlarval instars. Unknown. 


\section{Distribution}

Madagascar, only known from the areas of Antsiranana (formerly Diego Suarez) and Andrambovato.

Etymology

Latin: major. The name refers to the comparatively large size of the larva. The name is a case sensitive adjective.

Host

Rhagovelia adrienneaebrasili Poisson, 1945 (senior synonym of $R$. tesari flavomarginata Hoberlandt, 1951) §̊, Rhagovelia sp. (Hemiptera: Veliidae); larvae attached to sclerotised parts (cervix, pronotum and femora) (Figures $1 \mathrm{a}, \mathrm{b}$ ).

\section{Remarks}

Armaveliacola major differs from the other species of the genus in having nearly straight (versus curved) transverse ctenidial setae, combined with a larger scutum of length of $>200$ (versus < 180) $\mu \mathrm{m}$, setae $A M$ length $>90$ (versus < 90) $\mu \mathrm{m}$, distance $A M-A M,>90$ (versus < 90) $\mu \mathrm{m}, A L$ length $>100$ (versus $<100) \mu \mathrm{m}$, and distance $A L-A L>100($ versus $<100) \mu \mathrm{m}$.

\section{Armaveliacola minor sp. $\mathbf{n}$.}

Type locality

Cameroon, near Buea.

Type series

Holotype. Larva, Cameroon, near Buea, 21.VI.1973, leg. R.E. Linnavuori, detached from paratype of Rhagovelia linnavuorii Sallier-Dupin, 1979 (host MNHN 17819/APT), slide mounted (MNHN).

\section{Additional material}

Larva, Kenya, Kimba Hills, site 11, 10.XII.1989, leg. M. Jäch, detached from left femur II of Rhagovelia sp. $\stackrel{\curvearrowright}{\curvearrowright}$, slide mounted (NHMW).

\section{Description}

Larva. Metric data given in Table 2. Colour in life unknown. Idiosoma length in partly engorged larvae $480 \mu \mathrm{m}$. Shape and setation of sclerites (Figure 9a) as described for $A$. 
mirificus (see above). Eye sclerites length/width $28 / 20 \mu \mathrm{m}$, diameter anterior lens $10 \mu \mathrm{m}$, posterior $8 \mu \mathrm{m}$. Length $\mathrm{c}_{1}, 74 \mu \mathrm{m}$; $\mathrm{c}_{2}$ and $\mathrm{d}_{1-2}, 80-90 \mu \mathrm{m}$, dorsal setae $30-40 \mu \mathrm{m}$, diameter of setal platelets $10 \mu \mathrm{m}$, that of plate bearing $\mathrm{h}_{1} 15 \mu \mathrm{m}$.

Venter (Figure 10f) dominated by large coxal plates of legs I-III. Coxa I with clavate seta $1 b$ $(45-50 \mu \mathrm{m})$ and ctenidial seta $1 a$, latter with about 35 finger-like tines. Coxa II with setiform $2 a(30 \mu \mathrm{m})$ plus ctenidial seta $2 b$ with about 35 tines, coxa III with setiform $3 a(40 \mu \mathrm{m})$ and ctenidial seta $3 b$ with 30 tines. Anal sclerite length/width $80 / 36 \mu \mathrm{m}$, anal setae $40 \mu \mathrm{m}$, setae ps $45 \mu \mathrm{m}$.

Gnathosoma with $i c s$, length/width $100 / 125 \mu \mathrm{m}$, setae $c s 17 \mu \mathrm{m}$, spine-like setae $b s 10 \mu \mathrm{m}$. Palp femur seta length $10 \mu \mathrm{m}$, genu setae length $10-17 \mu \mathrm{m}$, tibia with 2 small setae $(6-8 \mu \mathrm{m})$ and 1 longer seta $(18 \mu \mathrm{m})$; odontus width $15 \mu \mathrm{m}$; tarsus with eupathidium $(6 \mu \mathrm{m})$, solenidion $\omega(6 \mu \mathrm{m})$ and 3 smooth setae $(4 \mu \mathrm{m})$.

Leg chaetotaxy as in Table 3. All legs with trochanter small, completely hidden in a cavity formed by laterodorsal extensions of coxae; basifemur conical, bent upwards shortly after base and widening distally; telofemur with 1 trichobothrium in dorsal position; legs I-III each with thin, elongate empodium and modified claw with a broadened base as described for $N$. johnstoni.

Postlarval instars. Unknown.

\section{Distribution}

Cameroon, Kenya.

\section{Etymology}

Latin: minor. The species name refers to the relatively small size of the larva. The name is a case sensitive adjective.

Host

Rhagovelia linnavuorii, R. sp. (Hemiptera: Veliidae); larvae attached to leg femora.

\section{Remarks}

Armaveliacola minor is similar to A. major in having straight ctenidial seta on coxae II and III. It differs from this and the other species in the small size of the seta on PaFe (10 versus $>$ $30 \mu \mathrm{m}$ in other species). 


\section{Armaveliacola rhagoveliae sp. $\mathbf{n}$.}

\section{Type locality}

Madagascar, Diego Suarez, precise locality unknown.

Type series

Holotype. Larva, Madagascar, Diego Suarez, precise locality unknown, 1893, leg. C.A. Alluaud, detached from Rhagovelia sp., slide-mounted (MNHN).

Paratype. Larva, 'Diego Suarez, sur Velia', together with 7 larvae of A. major, slide-mounted (19 C 12 from collection of Trouessart, dried and compressed) (MNHN).

\section{Description}

Larva. Metric data as in Table 2. Colour in life unknown. All sclerotised parts finely punctate, with an internal hexagonal reticulation. Idiosoma length $250 \mu \mathrm{m}$ (unfed) to $500 \mu \mathrm{m}$ (engorged); dorsum (Figure 9c) with scutum roughly rectangular, surface punctuate, with setulose setae AM, AL, PM and PL. Paired eyes on oval sclerites (length/width 30/18 $\mu \mathrm{m}$ ) at level of setae PM, hidden beneath scutum in unfed or partially fed larvae, anterior lens diameter $10 \mu \mathrm{m}$, posterior lens diameter $8 \mu \mathrm{m}$. Posterior to scutum is a pentagonal scutellum bearing 2 setulose setae $c_{1}(58 \mu \mathrm{m})$. Lateral to scutum and scutellum are 3 plates, each with 1 setulose seta $\left(\mathrm{c}_{2}, \mathrm{~d}_{1-2}, 70-80 \mu \mathrm{m}\right)$. Posterior dorsum with membranous, plicate cuticle. Dorsal setae $(20-30 \mu \mathrm{m})$ almost smooth, arranged in rows and situated on platelets $(8-10 \mu \mathrm{m})$; E row with $e_{1-} e_{2} ; F$ row with $f_{1-} f_{2} ; H$ row with $h_{1-2}$, setae $h_{1}$ located on a common plate $(15 \mu \mathrm{m}$ diameter).

Venter (Figures 9d, 10e) dominated by large coxal plates of legs I-III. Coxae I-III extended dorsolaterally, forming a posteriorly open sleeve completely covering the trochanter.

Laterodorsal margins of coxae abutting lateral borders of dorsal sclerites in unfed specimens. Coxa I bent ventrally in its anterior part; seta $1 b(75-80 \mu \mathrm{m})$ modified, thickened, clavate, distally with lamellate surface, inserting on a long tubercle; posterior to $l b$ is a strongly curved ctenidial seta ( $1 a$ ) with 30-35 finger-like tines. Coxa II with smooth seta $2 a(33 \mu \mathrm{m})$ plus ctenidial seta $(2 b)$, medially straight, laterally turned anteriorly, with about 35 finger-like tines and 2 Claparède's organs ( $c l p)$ at anterior margin. Coxa III directed posterolaterally, with smooth seta $3 a(40 \mu \mathrm{m})$, a strongly curved ctenidial seta $(3 b)$ with about 35 finger-like tines, and paired Claparède's organs $(c l p)$ at its anterior margin. Anal pore between coxae III, on an 
elongate (length/width $105 / 32 \mu \mathrm{m})$, undivided plate carrying 2 setulose setae $(35 \mu \mathrm{m})$. Membranous area posterior to anal sclerite plicate, with 2 setulose setae $p s(65 \mu \mathrm{m})$. Gnathosoma (Figures 9e-f) completely covered dorsally by ics (length/width 80/95 $\mu \mathrm{m}$ ). Anteroventrally with paired, smooth setae $c s(20 \mu \mathrm{m})$. Laterally, the palp femur fills the gap between the lateral extensions of coxae I and the posterolateral margins of the gnathosomal shield. Ventral part of gnathosoma with spine-like setae $b s(5 \mu \mathrm{m})$ just behind mouth opening. Chelicera with fine, slightly curved claw. Mouth opening surrounded by folded membrane that serves to seal insertion of chelicerae into the host cuticle. Palp formula 0-N-NN-NNNNNN $\omega \zeta$. Trochanter small, femur large, extended proximally and dorsally, with a prominent dorsolateral seta $(30 \mu \mathrm{m})$. Genu proximally with 2 smooth setae $(10-15 \mu \mathrm{m})$. Tibia comparatively short and robust, with 2 small $(7-10 \mu \mathrm{m})$ and 1 longer $(20 \mu \mathrm{m})$ seta laterally. Odontus undivided, broad (width $18 \mu \mathrm{m}$ ) and wedge-shaped, obviously as a result of the fusion of the previously bifid tips (see Isoveliacola). Tarsus with eupathidium (6 $\mu \mathrm{m})$, solenidion $\omega(6 \mu \mathrm{m})$ and 3 smooth setae $(4 \mu \mathrm{m})$.

Leg chaetotaxy as in Table 3 and Figures 9g-i. All legs with trochanter small, completely hidden in a cavity formed by laterodorsal extensions of coxae, bearing a small, hardly detectable spine-like seta (not shown in figures); basifemur conical, bent upwards shortly after base and widening distally; telofemur with 1 trichobothrium in dorsal position; legs I-III each with thin, elongate empodium and modified claw with a broadened base as described for N. johnstoni.

Postlarval instars. Unknown.

\section{Distribution}

Madagascar, Antsiranana (former Diego Suarez).

\section{Etymology}

The species name is derived from the name of the host genus. The name is a noun not in apposition.

\section{Host}

Rhagovelia sp. (Hemiptera: Veliidae); larvae attached to first abdominal segment. 


\section{Remarks}

Armaveliacola rhagoveliae differs from other species of the genus mainly in the strongly curved (as opposed to nearly straight) shape of the transverse ctenidial setae $1 \mathrm{a} / 2 \mathrm{a}$. Further differences are found in the shorter and closer setae AM, length $<70($ versus $>75) \mu \mathrm{m}$, distance $\mathrm{AM}-\mathrm{AM}<60$ (versus $>70) \mu \mathrm{m}$; AL length $<80$ (versus $>90) \mu \mathrm{m}$, distance AL-AL $<60$ (versus $>70) \mu \mathrm{m}$, PL length $<100$ (versus $>100) \mu \mathrm{m}$ and distance PL-PL $<150$ (versus $>150) \mu \mathrm{m}$.

\section{Unidentified parasitic mites in the USNM water bug collection}

All larvae examined from the USNM came from the dry insect collection. They were still attached to their insect hosts and in a poor condition (with legs and body fragmented after removal from host or specimen shrivelled with legs folded below the body), and are therefore not suited for description or to serve as type material. They are nevertheless reported here because they provide data of biogeographical interest (Table 1).

Archaeveliacola (?) sp. A

Material studied. Larva, 'Bolivia L.P., 24 km W Copriata, 2.-6.V.1969, leg. P. and P. Spangler', parasitic on Rhagovelia sp. (angustipes complex), base of head, detached and slide mounted. 3 larvae, Bolivia, Tres Estreos, Guanay, 19.-25.VIII.1989, leg. E. Perla, parasitic on Rhagovelia vivata Bacon, 1948, frons, detached and slide mounted (1 larva in dorsal position, others fragmented and with different orientations on the slide).

Remarks. Larvae with 2 pairs of Claparède's organs; trichobothrium on each telofemur; setulose setae on idiosoma and legs; ctenidial setae 1a, b; leg tarsi difficult to observe, apparently each leg with thin, elongate claw similar in shape to the empodium, without proximal extension. According to the observed characters, these larvae belong to Neolimnocharinae. The presence of cteniform setae on coxa I and the absence of ctenidial or taeniform structures on coxae II-III, as well as the absence of laterally enlarged gnathosoma shield, are character states typical for Archaeveliacola. However, the absence of proximal extensions of the claws of legs I-III suggests that it might belong in a different, undescribed genus.

Neolimnochares sp. B

Material studied. Larva, 'Peru, S.A. Cuzco, River Koros, 1.IV.1952, leg. F.L. Weytkowski', 
parasitic on Rhagovelia palea Bacon, 1956, left anterior pronotum, detached and slide mounted, fragmented.

Remarks. Larva with 2 pairs of Claparède's organs between coxae I/II; trichobothrium on each telofemur; setulose setae on idiosoma and legs; setae 1a, 1b, 2a, 3a on coxae I-III setiform, legs I-III each with thin, elongate empodium flanking a claw with proximal extension from which a hook arises about halfway along length of claw. The specimen resembles the larva of Neolimnochares johnstoni.

\section{Veliacola sp. A}

Material studied. 5 larvae, 'Dominican Republic, La Vega Province, El Rio (24 km NE), 12.XI.1984 P. and P. Spangler and R. Faitoute', parasitic on Rhagovelia tayloriella group (collaris species complex), dorsal thorax (numerous specimens), detached and slide-mounted. Remarks. Larvae with 2 pairs of Claparède's organs; trichobothrium on each telofemur; setulose setae on idiosoma and legs; ctenidial or palmate (not unambiguously detectable) setae $1 a, b$; taeniform setae on coxae II and III; leg tarsi, with thin, elongate empodium and 1 modified claw with proximal extension as described for $N$. johnstoni. The species closely resembles Veliacola mirificus, from which it differs by the proximally extended claw of leg III.

Neolimnocharinae (?) sp.

Material studied. Larva, 'U.S.A., Texas, Real Co., Ueces River, 3 miles south of Camp Wood, 12.XII.1984, D.A. and J.T. Polhemus', parasitic on Rhagovelia becki Drake and Harris, 1936, detached and slide mounted, legs either missing or not clearly visible.

Remarks. Based on its general appearance this specimen probably belongs to the Neolimnocharinae. However, because no determination to genus is possible, it is not listed in Table 1.

\section{Other taxa}

In addition to the neolimnocharines listed below, the material provides the first record of hydryphantoid larvae parasitic on Rhagovelia ('Mexico, Valles, 17.VII.1950, leg. C.J. Drake and F.C. Hottes', 2 larvae attached to left prothorax and left femur II of Rhagovelia formosa Bacon, 1956). A postlarval stage of a gamasid mite was found phoretic dorsally on abdomen 
of an unidentified gerrid ('Indonesia, Halamahera Isl., Wasile Distr., Kampung Labi-Labi, 27.V.1981, leg. A.C. McSmit and P.M. Taylor').

\section{Unidentified parasitic mite in OSU collection}

Isoveliacola sp. A

Material studied. Larva, Belize, Cayo District, Chiquibul National Park., Doyle's Delight, dry creek area, $16^{\circ} 29^{\prime} 23^{\prime \prime} \mathrm{N}, 89^{\circ} 02^{\prime} 45^{\prime \prime} \mathrm{W}, 950 \mathrm{~m}$ above sea level, 20.VIII.2007, leg. P.W. Kovarik, detached from veliid.

\section{Key to larvae of Limnocharidae}

(no descriptions available for species of Laterolimnochares and Austrolimnochares)

1 ...........Claws of legs I-II filiform, proximally not enlarged [subfamily Limnocharinae,

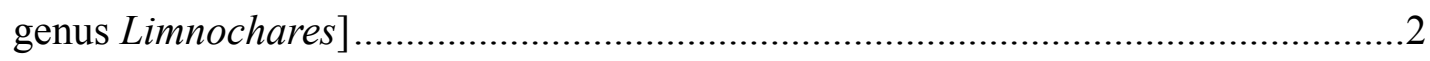

.Claws of legs I-II proximally enlarged (Figure 31 ) ...............................................

2 (1)....... Odontus of palp biramous (with equal-lengthed branches). Setae $1 a, 1 b$ located in distal half of coxa I. Gnathosoma bluntly rounded.

subgenus Limnochares (Limnochares) (larval stage only known for L. (L.) aquatica)

Odontus of palp simple. Seta $l a$ in proximal, seta $1 b$ in distal half of coxa I.

Gnathosoma tapered to the apex. [subgenus Limnochares (Cyclothrix)]....................3

3 (2) ......Scutum width $>100 \mu \mathrm{m}$. Distribution: North America

Limnochares (Cyclothrix) americana

- ...........Scutum width $<100 \mu \mathrm{m}$. Distribution: Asia, Africa.

Limnochares (Cyclothrix) crinita

4 (1).......Scutum with more than 12 setae [subfamily Rhyncholimnocharinae]

genus Rhyncholimnochares (only R. kittatinniana known for larval stage)

Scutum with 8 setae [subfamily Neolimnocharinae]

5 (4).......Setae $1 a$ and $1 b$ on coxa I strongly modified: $1 a$ cteniform (e.g., Figures $4 \mathrm{~b}, 8 \mathrm{~b}$ ), clavate (e.g., Figure 9e) or hamate (Figure 5g); 1 b cteniform (e.g., Figures 4b, 7e) or hamate (Figure 5g). Setae on scutum smooth (e.g., Figure 3a) or setulose (at least $A L)$ 
Setae $1 a$ and $1 b$ on coxa I normal (setiform) (e.g., Figure $2 b$ ). Setae on scutum smooth (Figure 2a) [genus Neolimnochares, in addition to the two species keyed out, a further record of an undefined species from Peru]

6 (5).......Coxae II-III with simple, unmodified seta s (e.g., Figure 3b) [genus

Archaeveliacola]

..Coxae II-III with strongly modified setae, either taeniform (e.g., Figures 5g, 5o) or ctenidial (e.g., Figures 7c, 9d)

7 (6).......Anal plate with 2 setae (Figure 4b). Empodia of tarsi I-III with basal extensions (Figures $4 \mathrm{~d}-\mathrm{e}$ ) Archaeveliacola smiti sp. n.

Anal plate without setae (Figure 3b). Empodia of tarsi I-III thin, without basal extensions (Figures 3d-e) Archaeveliacola papuanus sp. $\mathrm{n}$.

8 (6).......Coxal setae $l a$ and $l b$ palmate, coxal setae $2 b$ and $3 b$ taeniform (Figures $5 \mathrm{~g}, 5 \mathrm{o}$ ) [genus Veliacola].

Coxal setae $1 a$ and $1 b$ ctenidial or clavate, coxal setae $2 b$ and $3 b$ ctenidial (e.g.,

Figures $7 \mathrm{c}, 9 \mathrm{~d})$

9 (8).......Claws of legs III normal, not basally enlarged (Figure 5n) ...Veliacola mirificus $\mathrm{sp} . \mathrm{n}$.

Claws of legs III basally enlarged Veliacola sp. A (Bolivia)

10 (8).....Trochanter of legs I-III completely hidden in coxal cavities (Figure 9c). Setae $c_{1}$ on a common plate (Figures $9 \mathrm{a}-\mathrm{c}$ ). Coxa I with seta $1 a$ bearing 30 or more tines, seta $1 b$ club-like (Figures $8 \mathrm{e}, 9 \mathrm{e}$ ); with 4 pairs of Claparède's organs [genus Armaveliacola]

Trochanter of legs I-III only partly covered by coxae (Figures 6a, 7b). Setae $c_{1}$ on separate platelets (Figure $7 \mathrm{~b}$ ). Coxa I with seta $1 a$ bearing less than 10 tines, seta $1 b$ cteniform (Figure 6b); with 2 pairs of Claparède's organs [genus Isoveliacola] ...... 13

$11(10) \ldots$ Seta on palp femur small $(10 \mu \mathrm{m})$. Ctenidial setae weakly curved on all coxae (Figure 10f) Armaveliacola minor sp. n. Seta on palp femur large $(>30 \mu \mathrm{m})$. Ctenidial setae strongly curved on at least coxa III (Figures 9d, 10d-e). 
12 (11)...Setae $A L$ on scutum $\geq 100 \mu \mathrm{m}$, setae $A M \geq 90 \mu \mathrm{m}$. Ctenidial setae on coxae I-II straight, those on coxae 3 strongly curved (Figure 10d)... Armaveliacola major sp. n. Setae $A L$ on scutum $\leq 75 \mu \mathrm{m}$, setae $A M \leq 70 \mu \mathrm{m}$. Ctenidial setae on all coxae strongly curved (Figures 9d, 10e)........................... Armaveliacola rhagoveliae sp. n.

$13(10) \ldots$ Setae $A L \leq 35 \mu \mathrm{m}$, setae $A M \leq 30 \mu \mathrm{m}$ Isoveliacola costaricensis sp. $\mathrm{n}$. Setae $A L \geq 40 \mu \mathrm{m}$, setae $A M \geq 40 \mu \mathrm{m}$ Isoveliacola borneoensis $\mathrm{sp} . \mathrm{n}$.

$14(5) \ldots . .$. Seta $1 a$ located laterally on coxa $\mathrm{I}$, close to seta $1 b$ (Figure $2 \mathrm{~b}$ )

Neolimnochares johnstoni Seta $1 a$ located medially on coxa I Neolimnochares sp. A (Australia)

\section{Discussion}

\section{Interpretation of the modified coxal setae}

When the first specimens of Armaveliacola and Veliacola were examined, the nature of the strange structures on the leg coxae was unclear. While the clavate seta of coxa I looked like it might be a modified seta, the wide ctenidial and ribbon-like structures did not even vaguely resemble setae. The specimens were therefore examined in polarised light to determine whether these structures might be modified setae. As shown by Grandjean (1935a), the setae of actinotrichid mites contains a strongly birefringent material, which was originally called actinochitin (Grandjean, 1935b) and later renamed actinopilin (Grandjean in van der Hammen, 1961; Grandjean, 1970). This material is characterised by its optically negative activity, resistance to hypochlorites and idiophily. Another unusual feature of actinopilin in setae is that its optical axis is aligned radially relative to the long axis of a seta (Grandjean, 1935a; Hammen, 1961). Other structures of actinotrichid mites that contain this material include the tips of the cheliceral fingers, the leg claws and, when present, the rutella. Grandjean (1970) deduced from this that all these structures are derived from setae, even though this is no longer obvious from their gross morphology in most cases.

Examination in polarised light showed that the ctenidia on coxae I-III as well as the club shaped structure on coxa I are strongly birefringent (Figures 10a-f), indicating the presence of actinopilin. Assuming that the orientation of the material is the same as that in ordinary setae (in the case of the ctenidial setae, radially within the tines), its optical sign is negative. The optical activity of the taeniform structures on coxae II and III of Veliacola is rather different: 
they are only moderately birefringent and the optical sign seems to be reversed when the coxae are aligned in the same way as those of the other genera. However, we interpret this to mean that the actinopilin in these structures is no longer arranged radially, with the optical axis instead being parallel to the long axis of the ribbon-like base. The lower optical activity of the taeniform setae in polarised light is clearly due to their thinness. Although additional tests have not been carried out, we conclude from this strong birefringence that all these structures are modified setae. The homologies between them became easier to accept with the discovery of less extravagantly modified setae in Archaeveliacola, which provide an intermediate form between a peg-like seta and extreme ctenidial form seen in Armaveliacola. An additional argument in support of their homology is that the modified and normal setae are mutually exclusive: no case has been encountered in which the modified setae are present in addition to a full compliment of normal setae. Thus, if there is one modified seta on a coxa, there is never more than one ordinary seta, whereas if there are two setae of one type, there are none of the other. We are therefore confident that the modified setae are derived from the ordinary setae and have therefore applied the same standard notations to them.

\section{Biological remarks}

With the exception of Limnochares (Cyclothrix) spp. parasitising Odonata and Rhyncholimnochares kittatinniana parasitising Elmidae (Coleoptera) (Smith 1989b), gerromorph Hemiptera are used as host by the majority of Limnocharidae. Gerridae, which are regularly reported as hosts of Limnochares spp. (e.g., Böttger 1972, Smith 1989a), are also parasitised by Neolimnochares johnstoni larvae, sometimes together with Limnochares larvae (e.g., Figure 1b). Veliid bugs, which are restricted to running waters, are presently the only known hosts of Veliacola, Isoveliacola, Archaeveliacola and Armaveliacola. Given the failure to find larvae of these genera on other Gerromorpha, it seems likely that Veliidae represent the main or even only host group. It remains unknown whether this is linked with particular host recognition mechanisms of the water mite larvae, or particular behavioural or morphological peculiarities of the host. In Madagascar, adults of Neolimnochares were most frequently found in weakly seeping riparian springs of low order streams, habitats often associated with pool areas inhabited by populations of surface-dwelling insects. The only available paper dealing in detail with the life cycle of a Rhagovelia species (Cheng and Fernando 1971) does not deal with details of moulting. Both, in the field and in the laboratory, Rhagovelia nymphs 
are observed to stay closer to the riparian parts of streams and the early instars in particular do not mix with adults. As places for moulting they prefer objects such as rocks, floating twigs or leaves (A. Khila, in litt.). Our data strongly suggest that only adults are selected as hosts by the mites. In the abundant material of heteropteran larvae examined, not a single immature specimen was found to be parasitised. Enlarged sclerites (as in Veliacola and, particularly, Armaveliacola) may protect the water mite larvae against predation during host searching, and against grooming by the host after attachment. At a later stage of parasitism, the development of a stylostome (a feeding structure, ramified in Hydrachnoidea and Eylaoidea, that develops inside the host's tissues), will probably help fix the mite larva. Within Limnocharidae, such stylostomes are known for L. americana and L. aquatica (Smith 2003) and Rhyncholimnochares kittatinniana (Smith, unpubl. observation), but have not been investigated in other species. After attachment and the start of feeding, soft cuticle between the larval sclerites unfolds and allows for engorgement.

Legs are surely of importance during first attachment, but once the chelicerae have pierced the host's integument and the gnathosoma is fixed in a suitable position (as was the case in all studied specimens), the legs of most of the observed parasitising larvae were relaxed and extended from the body. Of definite importance for adhesion are the modified terminal palp segments, forming structures suitable for clasping and fixing to host setae. The clasping palps are fixed to fine setae visible under the anterior gnathosomal margin (Figure 5h). Once the mite larva has reached a suitable position on the host (in all cases directed anteriorly when attached to the body, and towards the coxae when fixed on legs), the closely appressed gnathosomal shield may protect the mite larva from being dislodged, e.g., during host cleaning. Almost nothing is known about host detection or mechanisms inducing detachment from hosts in neolimnocharines. Larvae of Neolimnochares johnstoni stay on the host after completing engorgement and moult to the calyptostatic protonymph while still attached to the host. For other Neolimnocharinae sufficient data are not available. In the material examined by us, larval exuviae were found on a few occasions, but never protonymphs.

\section{Relationships to other water mite taxa}

The presence of trichobothria on telofemora I-III of larvae, which is considered synapomorphic for Eylaoidea (Witte and Olomski, 1991), has been verified in Piersigia limophila Protz, 1896, Eylais extendens (Müller, 1776), E. hamata Koenike, 1897, E. setosa 
Koenike, 1897, Limnochares aquatica and L. crinita by Wiles (1993), for Rhyncholimnochares kittatinniana by Smith (1989b), for Apheviderulix welwitschioides Gerecke et al., 1999 (not mentioned in original description) and Neolimnochares johnstoni (this paper). For the remaining genera allocated to Eylaoidea (Laterolimnochares, Austrolimnochares, Rhyncheylais Lundblad, 1938, Austrapiersigia Smit, 1998, Stygolimnochares Cook, 1967, Parawandesia E. Angelier, 1951), larvae are either unknown or have not yet been examined for this character. Telofemoral trichobothria are only known from Eylaoidea within Parasitengona. In other water mite larvae, trichobothria are either located on the scutum (aerial larvae, e.g., of Hydryphantoidea) or absent (aquatic larvae of higher water mites). The statement by Gerecke et al. (2017: 620) that pedal trichobothria are present in hydryphantid larvae is erroneous. In terrestrial Parasitengona, only the Smarididae are known to have pedal trichobothria, but in this case they are located on the tarsus and tibia of leg I (Grandjean 1947, Wohltmann 2010). Based on the presence of larval telofemoral trichobothria, Veliacola, Archaeveliacola, Armaveliacola and Isoveliacola can be attributed to the Eylaoidea.

The presence of doubled Claparède's organs anterior to coxae II constitutes an additional character shared by Eylaoidea, though in this case a doubling of these organs is also known for larvae of other water mites outside Eylaoidea and has obviously evolved several times. Characters supporting the attribution of the rhagoveliid parasites to Limnocharidae are: (1) presence of only one claw on legs I-III (ancestral state: 2 claws, as in other Eylaoidea) and (2) presence of a large seta $k$ comparable in length to the nearby solenidion $\sigma$ on genua I and II (small and much shorter than $\sigma$ or absent in other Eylaoidea). (3) Within the Limnocharidae, Veliacola, Archaeveliacola, Armaveliacola and Isoveliacola agree with Rhyncholimnochares and Neolimnochares in having the claws on tarsus I-III with a broadened base, from which a hook arises about halfway along their length (other Limnocharidae and other families of Eylaoidea have the lateral claws filiform without a broadened base or are otherwise modified, as in Eylais Latreille, 1796). The presence of a filiform claw without such modification on leg III of Veliacola and the absence of modified claws in the larva from Belize listed as Archaeveliacola (?) sp. A seem to contradict this conclusion. However, these probably constitute reversals to the ancestral state, since other characters, such as the ctenidial setae, support a close relationship with other Neolimnocharinae, thus implying the presence of 
modified claws on all legs in the common ancestor of Neolimnocharinae. (4) With Neolimnochares johnstoni the larvae share the following characters: (A) formation of a common plate bearing $\mathrm{h}_{1}$ setae (if present, other Limnocharidae and other families of Eylaoidea have each $\mathrm{h}_{1}$ on a separate platelet), (B) presence of a distinct gnathosomal shield (other Limnocharidae and other families of Eylaoidea lack this shield). A common sclerite for setae $\mathrm{h}_{1}$ is not known in Isoveliacola borneoensis, but the area was difficult to observe in the two specimens available and no $h_{1}$ seta was detected at all.

\section{Relationships within the Neolimnocharinae}

Hitherto, a total number of 17 species are assigned to Neolimnochares, all known from postlarval instars (Table 1), but only $N$. johnstoni also from the larval stage. This genus is defined solely by the fusion of the palp femur and genu in deutonymphs and adults (Smith and Cook 2005a), but because some species show only partial fusion it has been suggested that the group might be polyphyletic in origin (Smith and Cook 2005a). Although considerable differences in the sclerotization of the idiosomal dorsum and the development of swimming setae have been reported (Smith and Cook 2005a and references therein, Tuzovskij and Gerecke 2009), relationships within the genus have not yet been analyzed.

Smith and Cook (2005b) noted that the study of larval morphology could improve our understanding of the relationships within this group. However, because most of the larvae described here have not been correlated with postlarval instars, it is not yet possible to resolve these problems. In terms of larval morphology, the monophyly of Neolimnocharinae is supported by the fusion of $h_{1}$ platelets; in other Limnocharidae setae $h_{1}$ are on separate plates (Limnochares) or missing (Rhyncholimnochares). The larval characters used by Smith and Cook (2005a) are not diagnostic for Neolimnocharinae because modified claws with a broadened base are also present in Rhyncholimnochares (Smith 1989b) and thus support a closer relationship of Rhyncholimnocharinae with Neolimnocharinae. A broad anal sclerite is absent in Archaeveliacola, from which it would appear that this character is of limited phylogenetic value.

Larvae assigned to Neolimnocharinae in the present paper display astonishingly high morphological diversity, which by far exceed the variability usually found in a mite genus and which resulted in the proposal of four new genera. Monophyly of the clade Archaeveliacola + Armaveliacola + Isoveliacola + Veliacola is supported by the presence a modified seta 1a, 
which is hamate in Veliacola and ctenidial in the other genera. The hamate setae of Veliacola can easily be derived from the ctenidial form by increasing the length of the base, although a transformation in the opposite sense is also conceivable. Based on the low number of tines in the ctenidial setae on coxa I and the absence of modified setae on coxae II-III, Archaeveliacola would appear to be the most plesiomorphic member of this clade. There is, however, a difficulty with interpreting the latter character because setae $2 b$ and $3 b$ are lacking in both Limnocharinae and Rhyncholimnocharinae. If Rhyncholimnocharinae and Neolimnocharitinae are sister-groups, it must be supposed that they have lost these setae independently, or else that these setae have somehow reappeared in the clade Armaveliacola + Isoveliacola + Veliacola. Within this group, Armaveliacola and Veliacola are probably more closely related to each other than to Isoveliacola, based on their increased sclerotization and stronger development of both the coxal extensions around the trochanters and the dorsal gnathosomal shield.

Based on these interpretations, evolution of larvae within Neolimnocharinae is characterised by trends towards the formation of specialised coxal structures and increasing sclerotization. Both traits are probably adaptations to their unusual hosts, but their exact significance remains unknown in the absence of behavioural data. It is interesting to note that modified coxal setae are also present in the eylaoid families Apheviderulicidae and Piersigiidae. In Piersigiidae, setae $1 \mathrm{a}, 1 \mathrm{~b}, 2 \mathrm{~b}$ and $3 \mathrm{~b}$ are peg-like, being shorter and thicker than normal setae (e.g., Imamura and Mitchell, 1967; Smith and Cook, 1991). In Apheviderulicidae, coxae I-III bear a large number of similar peg-like setae, with a lamellate surface, which have probably arisen through the multiplication of setae $1 b, 2 b$ and $3 b$ (Gerecke et al., 1999). Gerecke et al. (1999) suggested that the modified setae of Apheviderulicidae might be chemoreceptors, but an alternative interpretation is that they play a role in the initial attachment to the host. Presumably, these modifications have evolved independently, because only ordinary setae are present in the larvae of Limnochares and Neolimnochares.

\section{Biogeography}

The only known larva of Neolimnochares was reared from a North American species, leaving the possibility that it is not congeneric with the type species, N. petrophila (Lundblad, 1937), described from Brazil. All other species of the genus are only known from the adult stage. Based on our current knowledge, the separation from the other genera of the subfamily is only 
possible for the larval stage. Consequently, the true composition and distribution of Neolimnochares is uncertain at present.

Neolimnocharine taxa described from larvae are known from most of the continents from which adult Neolimnochares have been described. Thus there are four larval species of Armaveliacola and Veliacola, and six adult Neolimnochares species known from Africa; two larval species of Archaeveliacola and Isoveliacola from Asia; two larval species of Neolimnochares and Archaeveliacola, and two adult Neolimnochares species from Oceania (including Australia); three larval species of Neolimnochares and Isoveliacola (one possibly representing an undescribed genus), and five adult Neolimnochares species from South America; from North America, in addition to Neolimnochares johnstoni, the only species described for larvae and adults, there is one undescribed larval species of Veliacola (Table 1). In Madagascar, the species Neolimnochares madagascariensis Tuzovskij and Gerecke 2009 and $N$. longirostris Tuzovskij and Gerecke 2009 were both described from adults found in the same stream system in which the larva of Veliacola mirificus was found. However, larvae of the two closely related species Armaveliacola major and A. rhagoveliae were also collected in the same mountain range, Montagne d'Ambre (and possibly in the same catchment), so it would be unwise to propose any correlation between the larvae and adults.

Several attempts were made during the five years following the first sampling of larvae to establish correlations between adults and larvae through rearing or molecular analyses, but all were unsuccessful. Thus, we have to accept that at least some of the species described here will turn out to be synonyms of those previously described from postlarval instars.

We are acutely aware that the larval-based taxonomy presented here results in a parallel system in Limnocharidae, for which taxa have previously been based on adults. Such 'double' taxonomies have long existed in several groups of terrestrial Parasitengona in which most species of some groups are described for the larva only (Mąkol and Wohltmann 2012). Although this situation is undesirable, it is inevitable in groups where different stages are difficult to associate. This problem is gradually being resolved for through laboratory rearing and molecular analysis (Stålstedt et al. 2016). One of the reasons that we have decided to publish new taxa here is that our results suggest that the morphology of larval stage in the taxonomy of limnocharids (Smith 1989b), and possibly also of other clades of early derivative water mites (Eylaidae: Lanciani 1969), appears to be more informative than that of 
deutonymphs and adults for delimiting genera. We also hope that the publication of the present results will stimulate new field and laboratory work on these interesting Rhagovelia parasites and hence lead to correlations of the larvae with adults.

\section{Acknowledgements}

Monika Meinert (University of Tübingen) helped with preparation of specimens for SEM investigation and gave patient assistance during the photographic sessions. Laurent Fauvre (MNHN) kindly provided high resolution photographs of parasitised Rhagovelia from the MNHN collection. Invaluable support was provided by the curators of the entomology collections at Frankfurt (Massimo Terragni, SMF), Munich (Michael Balke, ZSM), Paris (Eric Guilbert, MNHN), Vienna (Herbert Zettel, NHMW) and Washington (Thomas J. Henry, USNM). Abderrahman Khila (Lyon) gave us information on the behaviour of Rhagovelia. Hans Klompen (Ohio State University) kindly provided information on material collected by P.W. Kovarik in Belize. Harry Smit (Leiden) gave helpful comments on a former draft of this paper.

Herbert Zettel (NHMW) gave additional support by checking and updating the nomenclature of the hemiptera taxa treated.

Attempts (unfortunately unsuccessful) to obtain molecular sequences were made by Lucas Blattner (Basel), Michael Laumann (Tübingen/Konstanz) and Jerôme Morinière (Munich). We are thankful for their efforts.

\section{Funding}

Preparative work for this study was done by R.G. during two EU projects (PARSYST 2000, SYNTHESYS 2011); in 2011 costs for field work in Madagascar (expenses for travelling, logistics, and preliminar molecular studies) were covered by a grant of Deutsche Forschungsgemeinschaft (Ge 646/16/1). Further elaboration of the results was made by R.G. during work at MNHN as an invited researcher in May/June 2012.

\section{Authors' contributions}

The discussion of the results and drafting of the final version of the manuscript was jointly carried out by all authors. Individual contributions were as follows: drawings by A.W. and B.P.S.; photography in polarised light by M.J.; SEM investigation by R.G.; field work in Madagascar by R.G. (in cooperation with R. Oliarinony and R. Ranaivosolo of the University 
of Antananarivo); museum work by M.J. and R.G.; field and laboratory studies on Neolimnochares johnstoni by B.P.S.

\section{Declaration of interest}

The authors declare that they have no competing interests.

\section{References}

Angelier, E. (1935b), 'Diagnoses Sommaires d'Hydracariens Psammiques Nouveaux de Corse', Bulletin du Muséum national d'Histoire Naturelle de Paris (2) 23 (5), 508-510.

Bader, C. (1978), 'Eine neue Limnochariden-Art von den Seychellen', Revue de Zoologie Africaine, 92 (2): 421-430.

Barr, D., and Smith, B.P. (1979), 'The Contribution of Setal Blades to Effective Swimming in the Aquatic Mite Limnochares americana (Acari: Prostigmata: Limnocharidae)', Zoological Journal of the Linnean Society, 63: 55-59.

Böttger, K. (1972), 'Vergleichend Biologisch-Ökologische Studien zum Entwicklungszyklus der Süßwassermilben (Hydrachnellae, Acari). I. Der Entwicklungszyklus von Hydrachna globosa und Limnochares aquatica', Internationale Revue der Gesamten Hydrobiologie, 57 (1): 109-152.

Cheng, L., and Fernando, C.H. (1971), 'Life History and Biology of the Riffle Bug Rhagovelia obesa Uhler (Heteroptera: Veliidae) in Southern Ontario', Canadian Journal of Zoology, 49: 435-442.

Cook, D.R. (1966), 'The Water Mites of Liberia', Ann Arbor, Michigan: Memoirs of the American Entomological Institute, 6.

Cook, D.R. (1967), 'Water Mites from India', Ann Arbor, Michigan: Memoirs of the American Entomological Institute, 9.

Cook, D.R. (1974), 'Water Mite Genera and Subgenera', Ann Arbor, Michigan: Memoirs of the American Entomological Institute, 21.

Cook, D.R. \& Bright, G.R. (1983), 'Water Mites of the Palau Islands', Acarologia, 24 (2), 187-201.

Crowell, R.M. (1963), 'The Developmental Stages of a Water Mite, Limnochares americana, Parasitic on Damselflies (Coenagrionidae)', in Advances in Acarology Vol.1., ed. J.A. Naegele, Ithaca, NewYork: Comstock Publishing Associate, pp. 131-134. 
Gerecke, R. (2004), 'The Water Mites of Madagascar (Acari: Hydrachnidia): a Revised List Completed by Original Material Conserved at the Muséum National d'Histoire Naturelle, Paris', Zoosystema, 26 (3), 393-418.

Gerecke, R., Judson, M., and Cook, D.R. (2017), 'Synonymy of the Water Mite Families Malgasacaridae and Zelandothyadidae (Acari: Hydrachnidia) Reveals an Interesting Disjunct Distribution in the Southern Hemisphere', Acarologia 57 (3), 617-631.

Gerecke, R., Smith, I.M., and Cook, D.R. (1999), 'Three new Species of Apheviderulix gen. nov. and Proposal of Apheviderulicidae fam. nov. (Acari: Hydrachnidia: Eylaoidea)', Hydrobiologia, 397: 133-147.

Grandjean, F. (1935a), 'Les Poils et les Organes Sensitifs Portés par les Pattes et le Palpe chez les Oribates', Bulletin de la Société zoologique de France, 60 (1), 6-39.

Grandjean, F. (1935b), 'Observations sur les Acariens, 1er Série', Bulletin du Muséum national d'Histoire Naturelle de Paris (2) 7 (2), 119-126.

Grandjean, F. (1947), 'Étude sur les Smarisidae et Quelques Autres Erythroides (Acariens) ', Archives de Zoologie Experimentale et Générale, 85 (1), 1-126.

Grandjean, F. (1970), 'Stases. Actinopilin. Rappel de ma Classification des Acariens en 3 Groupes Majeurs. Terminologie en Soma', Acarologia, 11 (4) [1969], 796-827. Grube, A.E. (1859), 'Verzeichnis der Arachnoiden Liv-, Kur- und Ehstlands', Archiv für Naturkunde Liv-, Ehst- und Kurlands, (s. 2), 1: 417-486.

Hammen, L. van der, (1961), 'Description of Holothyrus grandjeani nov. spec. and Notes on the Classification of the Mites', Nova Guinea. Zoology, 9, 173-194, pl. 6.

Habeeb, H. (1954), 'North American Hydrachnellae, Acari. IX-XVI', Leaflets Acadian Biology, 2, 1-14.

Harvey, M.S. (1990), 'A Review of the Water Mite Family Limnocharidae in Australia (Acarina)', Invertebrate Taxonomy, 3: 483-493.

Harvey, M.S. (1998) 'The Australian Water Mites. A Guide to Families and Genera', CSIRO Publishing, Collingwood, Monographs on Invertebrate Taxonomy 4.

Imamura, T., and Mitchell, R. (1967), 'The ecology and life cycle of the water mite, Piersigia limophila Protz', Annotationes zoologicae Japonenses, 40 (1), 37-44.

International Commission on Zoological Nomenclature (1999), 'International code of zoological nomenclature' (4th ed.), London, TX. 
Jin, D. (1999), 'Laterolimnochares huangshanensis gen. nov. et sp. nov. of Limnocharidae from Huangshan, Anhui (Acari: Eylaoidea)', Acta entomologica Sinica, 42 (3), $311-314$

Koenike, F. (1897), 'Zur Systematik der Gattung Eylais Latr. (Vorläufige Mittheilung).', Abhandlungen des Naturwissenschaftlichen Vereins zu Bremen, 14, 279-295.

Koenike, F. (1898), 'Hydrachniden-Fauna von Madagaskar und Nossi-Bé', in Wissenschaftliche Ergebnisse der Reisen in Madagaskar und Ostafrika in den Jahren 1889-95 (Heft II), ed. Voeltzkow, A., Abhandlungen der Senckenbergischen Naturforschenden Gesellschaft, 21 (2), 297-435, pls XX-XXIX.

Lanciani, C.A. (1969), 'Three Species of Eylais (Acari: Eylaidae) Parasitic on Aquatic Coleoptera', Transactions of the American Microscopical Society, 88 (3), 356-365. Latreille, P.-A. (1796), 'Précis des Caractères Génériques des Insectes, disposes dans un ordre naturel', Prévôt, Paris.

Leach, W.E. (1816), 'A Tabular View of the External Characters of four Classes of Animals, which Linné Arranged Under Insecta; with the Distribution of the Genera Composing three of these Classes into Orders, \&c. and Descriptions of Several new Genera and Species', Transactions of the Linnean Society of London, 11, 306-400.

Linnaeus, C. (1758), 'Systema Naturae’, ed. 10, reformata, 1, Zoologie. Holmiae: Laur. Salvii.

Lundblad, O. (1936), 'Dritte Mitteilung über neue Wassermilben aus Santa Catharina in Südbrasilien', Zoologischer Anzeiger, 116 (7-8), 200-211.

Lundblad, O. (1938), 'Neue Wassermilben aus Paraguay', Zoologischer Anzeiger, 122 (1-2), $7-19$.

Lundblad, O. (1937), 'Fünfte Mitteilung über neue Wassermilben aus Santa Catharina in Südbrasilien', Zoologischer Anzeiger, 120 (11-12), 280-293.

Lundblad, O. (1941a), 'Neue Wassermilben. Vorläufige Mitteilung', Entomologisk Tidskrift, $62(1-2), 97-121$.

Lundblad, O. (1941b), 'Neue Wassermilben aus Amerika, Afrika, Asien und Australien', Zoologischer Anzeiger, 133 (7-8), 155-160.

Lundblad, O. (1941c), 'Die Hydracarinenfauna Südbrasiliens und Paraguays. Erster Teil', Kungliga Svenska Vetenskapsakademiens Handlingar, (3) 19 (7): 1-183, pls I-V. 
Lundblad, O. (1967), 'Wassermilben von Hinterindien', Arkiv för Zoologi, (2) 19 (21), 391419.

Lundblad, O. (1969), 'Indische Wassermilben, Hauptsächlich von Hinterindien', Arkiv för Zoologi, 22 (10), 289-443.

Mąkol, J., and Wohltmann, A. (2012), 'An Annotated Checklist of Terrestrial Parasitengona (Actinotrichida: Prostigmata) of the World, Excluding Trombiculidae and Walchiidae', Annales Zoologici 62(3), 359-562.

Martin, P., and Smit, H. (2002), 'The Larval Morphology and Host of the Australian Water Mite Limnochares australica (Acari: Hydrachnidia: Limnocharidae)', Records of the Western Australian Museum, 20, 409-414.

Mayr, G.L. (1865), 'Diagnosen neuer Hemipteren II', Verhandlungen der kaiserlichköniglichen Zoologisch-Botanischen Gesellschaft in Wien, 15: 429-446.

Müller, O.F. (1776) 'Zoologiae Danicae prodromus, seu animalium Daniae et Norvegiae indigenarum characteres, nomina, et synonyma imprimis popularium' Havniae: Hallager.

Orghidan, T., and Georgesco, M. (1977), 'Hydracariens de Cuba. Espèces Nouvelles de neolimnochares et de Wandesia', Résultats des expéditions biospéologiques Cubanoroumaines, 2, 209-215.

Prasad, V. (1982a), 'Some Evidences of Morphological Characteristics in the Water Mite Larvae (Acarina: Hydracarina). Part I', International Journal of Acarology, 8 (3), 181187.

Prasad, V. (1982b), 'Some Evidences of Morphological Characteristics in the Water Mite Larvae (Acarina: Hydracarina). Part II', International Journal of Acarology, 8 (3), 197-203.

Prasad, V., and Cook, D.R. (1972), 'The Taxonomy of Water Mite Larvae’ Ann Arbor, Michigan: Memoirs of the American Entomological Institute, 18.

Protz, A. (1896), 'Beiträge zur Kenntnis der Wassermilben', Zoologischer Anzeiger, 19 (513), $407-411$.

Raphael, S. (1970), 'The Publication Dates of the Transactions of the Linnean Society of London, Series I, 1791-1875', Biological Journal of the Linnean Society, 2, 61-76.

Smit, H. (1998), 'A new Genus of the Water Mite Family Piersigiidae from Australia (Acari: Hydrachnidia)', Records of the Western Australian Museum, 19, 107-110. 
Smith, B.P. (1989a), 'Impact of Parasitism by Larval Limnochares aquatica (Acari: Hydrachnidia; Limnocharidae) on Juvenile Gerris comatus, Gerris alacris and Gerris nuenoi (Insecta: Hemiptera; Gerridae)', Canadian Journal of Zoology, 67, 2238-2243.

Smith, B.P. (1989b), 'A Description of the Larva of Rhyncholimnochares kittatinniana Habeeb (Hydrachnidia; Limnocharidae)', Canadian Entomologist, 121, 445-452.

Smith, B.P. (2003), 'Diversity of Stylostome Structure among Parasitic Larval Water Mites (Prostigmata: Hydrachnidia)', in An acarological tribute to David R. Cook - From Yankee Springs to Wheeny Creek, ed. Smith I.M, West Bloomfield, Michigan: Indira Publishing House, pp. 239-255.

Smith, B.P., and Barr, D. (1977), 'Swimming by the Water Mite Limnochares americana Lundblad (Acari: Parasitengona: Limnocharidae).' Canadian Journal of Zoology, 55: 2050-2059.

Smith, I.M., and Cook, D.R. (2005a), 'Systematics of Stream-Inhabiting Species of Limnochares (Acari: Eylaoidea: Limnocharidae) in North America', International Journal of Acarology, 31 (4), 379-385.

Smith, I.M., and Cook, D.R. (2005b), 'Description of a New Species of Neolimnochares (Acari: Eylaoidea: Limnocharidae) from Eastern North America', International Journal of Acarology, 31 (4), 387-392.

Smith, I.M., Cook, D.R., and Smith, B.P. (2001), 'Water mites (Hydrachnida) and Other Arachnids' in Ecology and Classification of North American Freshwater Invertebrates, 2nd edition, eds J.H. Thorp and A.P. Covich, San Diego: Academic Press, pp. $551-659$.

Smith, I.M., Cook, D.R., and Smith, B.P. (2010), 'Water mites (Hydrachnida) and Other Arachnids' in Ecology and Classification of North American Freshwater Invertebrates, 3rd edition, eds J.H. Thorp and A.P. Covich, San Diego: Academic Press, pp. $485-586$.

Sparing, I. (1959), 'Die Larven der Hydrachnellae, ihre Parasitische Entwicklung und ihre Systematik', Parasitologische Schriftenreihe, 10, 1-168.

Stålstedt, J., Wohltmann, A., Bergsten, J., and Mąkol, J. (2016), 'Towards Resolving the Double Classification in Erythraeus (Actinotrichida: Erythraeidae): Matching Larvae with Adults Using 28S Sequence Data and Experimental Rearing', Organisms Diversity \& Evolution, 16 (4), 761-790. 
Tuzovskij, P.V. (1987), 'Morphology and Postembryonic Development of Water Mites', Nauka, Moscow [in Russian].

Tuzovskij, P.V. (2008), 'A New Water Mite Species of the Genus Neolimnochares from Ecuador', Zoosystematica Rossica, 17 (1): 11-14

Tuzovskij, P.V., and Gerecke, R. (2009), 'Water Mites of the Family Limnocharidae (Acariformes: Hydrachnidia) from Madagascar', Acarina, 17 (1), 33-55.

Vercammen-Grandjean, P.H. (1980), 'Analyse Critique de la Systématique de deux Sousfamilies d'Hydracariens: Wandesiinae Schwoerbel, 1961 et Stygothrombiinae Thor, 1935', Folia Parasitologica, 27, 151-164.

Viets, K. (1914), 'Hydracarinen aus dem Kaplande. Gesammelt von der Deutschen SüdpolarExpedition', Zoologische Jahrbücher. Abteilung für Systematik, Ökologie und Biologie der Tiere, 37 (4), 329-350.

Viets, K. (1953), 'Die aus Afrika bekannten Wassermilben (Hydrachnellae, Acari)', Hydrobiologia, 5 (1-2), 1-178.

Viets, K. (1914), 'Wassermilben aus dem Amazonasgebiet (Hydrachnellae, Acari) (Systematische und ökologische Untersuchungen.) Bearbeitung der Sammlungen Dr. R. Braun, Aarau, und Dr. H. Sioli, Bélem', Schweizerische Zeitschrift für Hydrologie, $16(1), 78-151$.

Wainstein, B.A. (1965), 'Materials on the Biology and Systematics of the Water Mites (Hydrachnellae): IV. The larva of Hydrachna cruenta Müller, 1776. V. The larva of Limnochares aquatica (L., 1758)', Institut Biologii Vnutrennych Vod, Trudy, 8 (11), 84-90 [in Russian].

Wainstein, B. A. (1980), The Determination of Larvae of Water Mites, Institut Biologii Vnutrennych Vod; Nauka, Moscow [in Russian].

Walter, C., and Bader, C. (1953), 'Hydracarinen aus Madagascar', Mémoires de l' Institut Scientifique de Madagascar, s. A (8), 67-72.

Wiles, P.R. (1993), 'Larval Descriptions of three Asian Watermites (Acari: Hydrachnida):

Diplodontus haliki Lundblad, Limnochares crinita Koenike and Hydryphantes incertus Koenike', International Journal of Acarology, 19 (4), 355-363.

Witte, H., and Olomski, R. (1991), 'Outlines on the Phylogenetic System of Freshwater Mites (Acari, Parasitengonae, Hydrachnidia)', Verhandlungen der Deutschen Zoologischen Gesellschaft, 84: 450 . 
Wohltmann, A. (2001), 'Closely related species of Parasitengonae (Acari: Prostigmata) inhabiting the same area: patterns facilitating coexistence' in Acarology: Proceedings of the 10th International Congress of Acarology, eds R.B. Halliday, D.E. Walter, H.C. Proctor, R.A. Norton, and M.J. Colloff. Melbourne, CSIRO Publishing, pp. 121-135. Wohltmann, A. (2010), 'Notes on the Taxonomy and Biology of Smarididae (Acari: Prostigmata: Parasitengona)', Annales Zoologici, 60 (3), 355-381.

Wohltmann, A., Gabryś G., and Mąkol, J. (2007), 'Terrestrial Parasitengona Inhabiting Transient Biotopes', in Süßwasserfauna Mitteleuropas, Vol. 7/2-1, Chelicerata, Acari I. ed. Gerecke, R., Munich, Spektrum Elsevier, pp. 158-240.

Wolcott, R.H. (1905), 'A Review of the Genera of the Water Mites, Transactions of the American Microscopical Society, 26, 161-243. 


\section{Captions for figures}

Figure 1. Neolimnocharine larvae parasitising water bugs: $(\mathrm{a}, \mathrm{b})$ Armaveliacola major sp. $\mathrm{n}$. paratypes attached to Rhagovelia sp. (MNHN); (a) dorsal view (inset: original labels); (b) other host specimen, lateral view; (c) Neolimnochares johnstoni Smith and Cook, 2005, larva (right) attached to Gerris comatus Drake and Hottes, 1925, together with two larvae of Limnochares aquatica (Linnaeus, 1758) located dorsally; (d) Veliacola mirificus sp. n. paratype on Rhagovelia sp., femur; (e, f) Archaeveliacola papuanus sp. n. paratypes attached to Rhagovelia sp.; (e) three variously engorged specimens; (f) single specimen at higher magnification.

Figure 2. Neolimnochares johnstoni Smith and Cook, 2005, larva: (a) dorsal view, legs omitted; (b) ventral view, legs omitted beyond coxae; (c) dorsal view of gnathosoma; (d) ventral view of gnathosoma (right: detail of palp tarsus enlarged); (e) leg I; (f) leg II; (g) leg III. Bars: $100 \mu \mathrm{m}$.

Figure 3. Archaeveliacola papuanus sp. n., larva: (a) dorsal view, legs omitted beyond trochanter; (b) ventral view, legs omitted beyond coxa; (c) gnathosoma ventral; (d) legs I and II with their coxae - details: tarsi, unspecialised setae omitted; (e) leg III with coxa - detail: tarsus III, unspecialised setae omitted; (f-l) SEM; (f) dorsal view; (g) ventral view; (h) detail, coxae I and II; (i) gnathosoma dorsal; (k) palp tarsus carrying spine-like setae (sp), eupathidium $(\zeta)$ and solenidion $(\omega)$; (1) tip of tarsus I with claw and empodium. Bars (unless otherwise stated): $100 \mu \mathrm{m}$.

Figure 4. Archaeveliacola smiti sp. n., larva: (a) dorsal view, legs omitted beyond telofemur; (b) ventral view, legs omitted beyond trochanter; (c) palp femur, genu, tibia, tarsus, detail of odontus; (d) legs I-II with their coxae - detail: tarsus I, unspecialised setae omitted, and claws of leg I; (e) leg III. Bars: $100 \mu \mathrm{m}$. 
Figure 5. Veliacola mirificus sp. n., larva: (a) habitus, dorsal view; (b) ventral view of gnathosoma, below details of palp tibia and tarsus, enlarged, not to scale; (c) leg Iwithout coxa, at left telofemur-tarsus with only specialised setae shown; (d) leg II without coxa, at right telofemur-tarsus with only specialised setae shown; (e) leg III without coxa, at right telofemur-tarsus with only specialised setae shown; (f) dorsal view, legs omitted beyond basifemur; (g) ventral view, legs omitted beyond basifemur; (h-o) SEM; (h) attached to its host, posterolateral view; (i) attached to its host, dorsal view, $(\mathrm{ics}=$ gnathosomal shield, $\mathrm{bs}=$ bases of chelicerae, $\mathrm{sc}=$ scutum, $\mathrm{h} 1=$ posterior plate carrying $\mathrm{h}_{1}$ setae); (k) details of palp odontus; (l) tarsus leg II; (m) femur-tibia leg I with labelled specialised setae; (n) tarsus leg III; (o) ventral view. Bars (unless otherwise stated): $100 \mu \mathrm{m}$.

Figure 6. Isoveliacola spp. larvae, SEM: (a-d) I. borneoensis sp. n.; (a) dorsolateral view; (b) oblique ventral view; (c) frontal view with dorsal gnathosomal shield (ics), bases of chelicerae (cb) and arrangement of palp femur (PaFe) and palp genu (PaGe); (d) detail of palp tarsus; (e) I. costaricensis sp. n., engorged specimen attached to prosternum of Rhagovelia sp.

Figure 7. Isoveliacola costaricensis sp. n., larva: (a) engorged specimen, dorsal view, legs omitted beyond telofemur; (b) slightly engorged specimen, dorsal view, legs omitted beyond basifemur; (c) slightly engorged specimen, ventral view, legs omitted beyond basifemur; (d) ventral view of gnathosoma, at right: detail of palp tarsus enlarged, not to scale; (e) coxae I, II with legs I-II, above detail of tarsus I with only specialised setae shown, at right telofemur II-tarsus II with only specialised setae shown; (f) coxa III with leg III, at right tarsus III with only specialised setae shown. Bars: $100 \mu \mathrm{m}$.

Figure 8. Armaveliacola major sp. n., larva, SEM: (a) dorsal view; (b) gnathosoma and region of coxae I, ventrolateral view; (c) seta 1a on coxa I; (d) detail of c, tips of extensions; (e) distal part of seta $1 \mathrm{~b}$ on coxa I. 
Figure 9. Armaveliacola spp., larvae: (a) A. minor sp. n., dorsal view, legs omitted beyond basifemur; (b) A. major sp. n., dorsal view, legs omitted beyond basifemur; (c-i) $A$. rhagoveliae sp. n.; (c) dorsal view, legs omitted beyond basifemur; (d) ventral view, legs omitted beyond basifemur; (e) ventral view of gnathosoma and region of coxae I; (f) detail of palp genu, tibia and tarsus; detail: odontus; (g) leg I, at right genu-tarsus I with only specialised setae shown; (h) leg II, at right genu-tarsus II with only specialised setae shown; (i) leg III. Bars: $100 \mu \mathrm{m}$.

Figure 10. Neolimnocharinae larvae ventral view, photographs at polarised light showing birefringent variously modified setae 1a, b, 2b, 3b: (a) Veliacola mirificus sp. n., holotype; (b) Isoveliacola borneensis sp. n., holotype; (c) I. costaricensis sp. n., holotype; (d) Armaveliacola major sp. n., paratype; (e) A. rhagoveliae sp. n., holotype; (f) A. minor sp. n., holotype. 


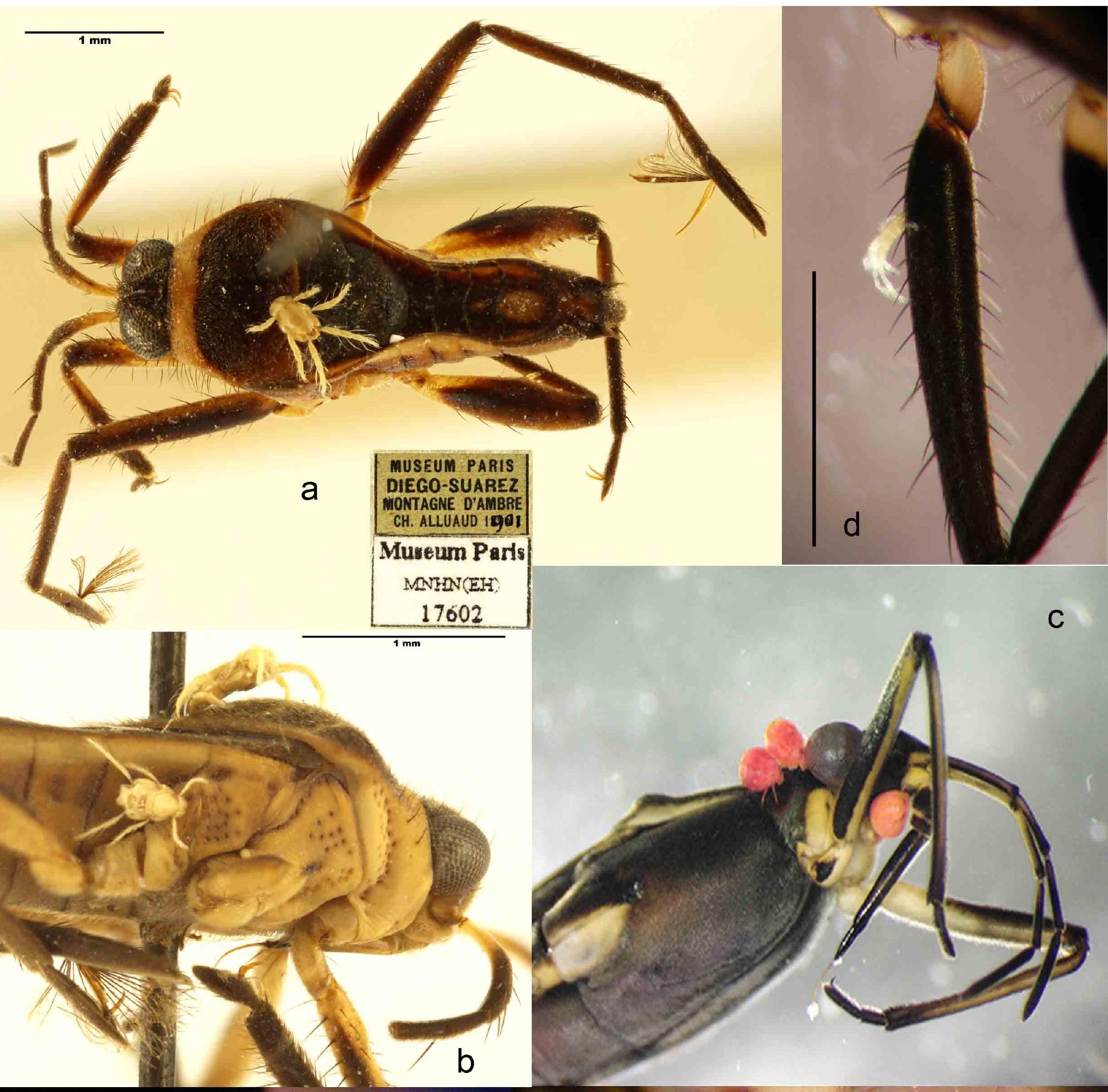




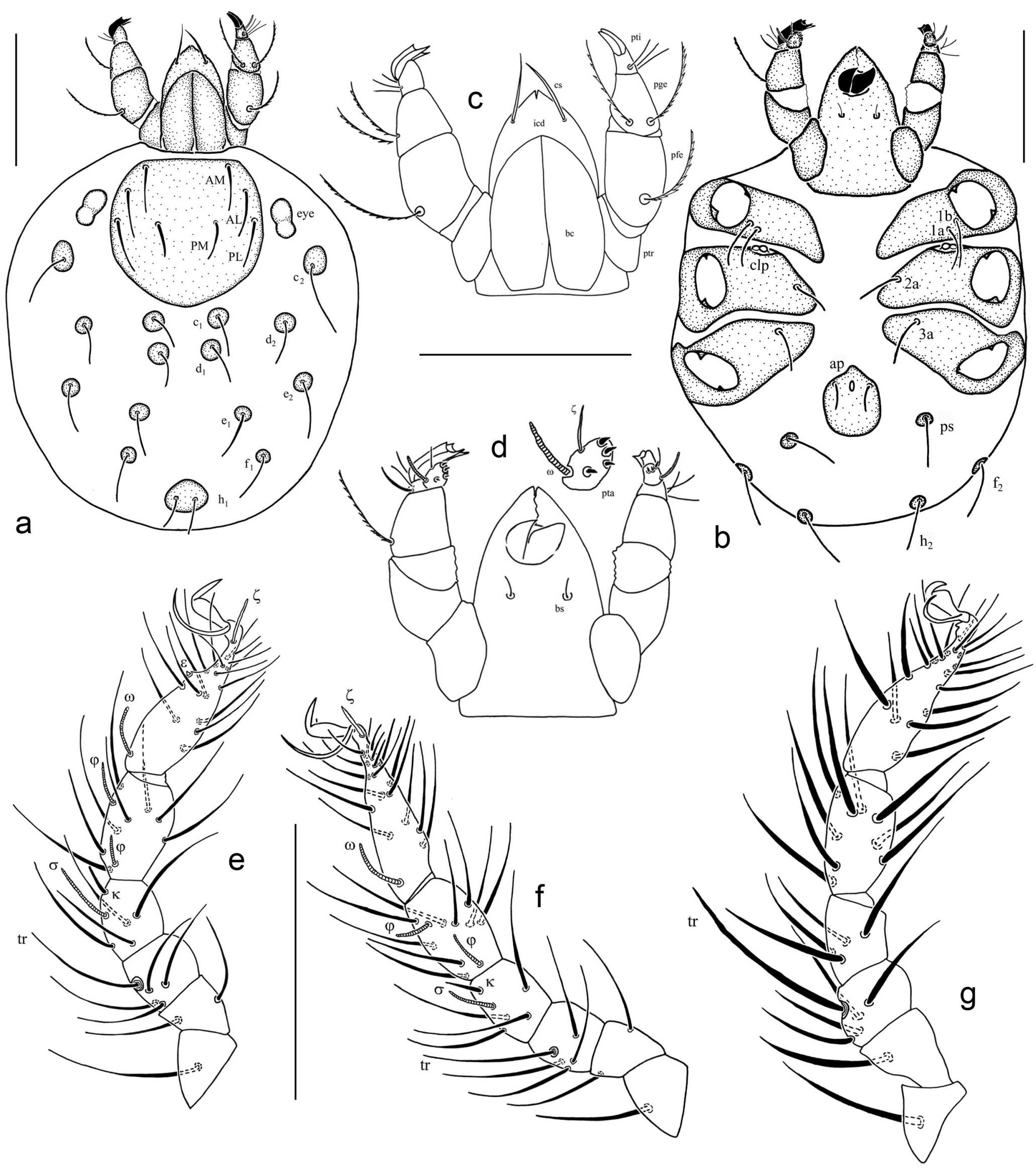




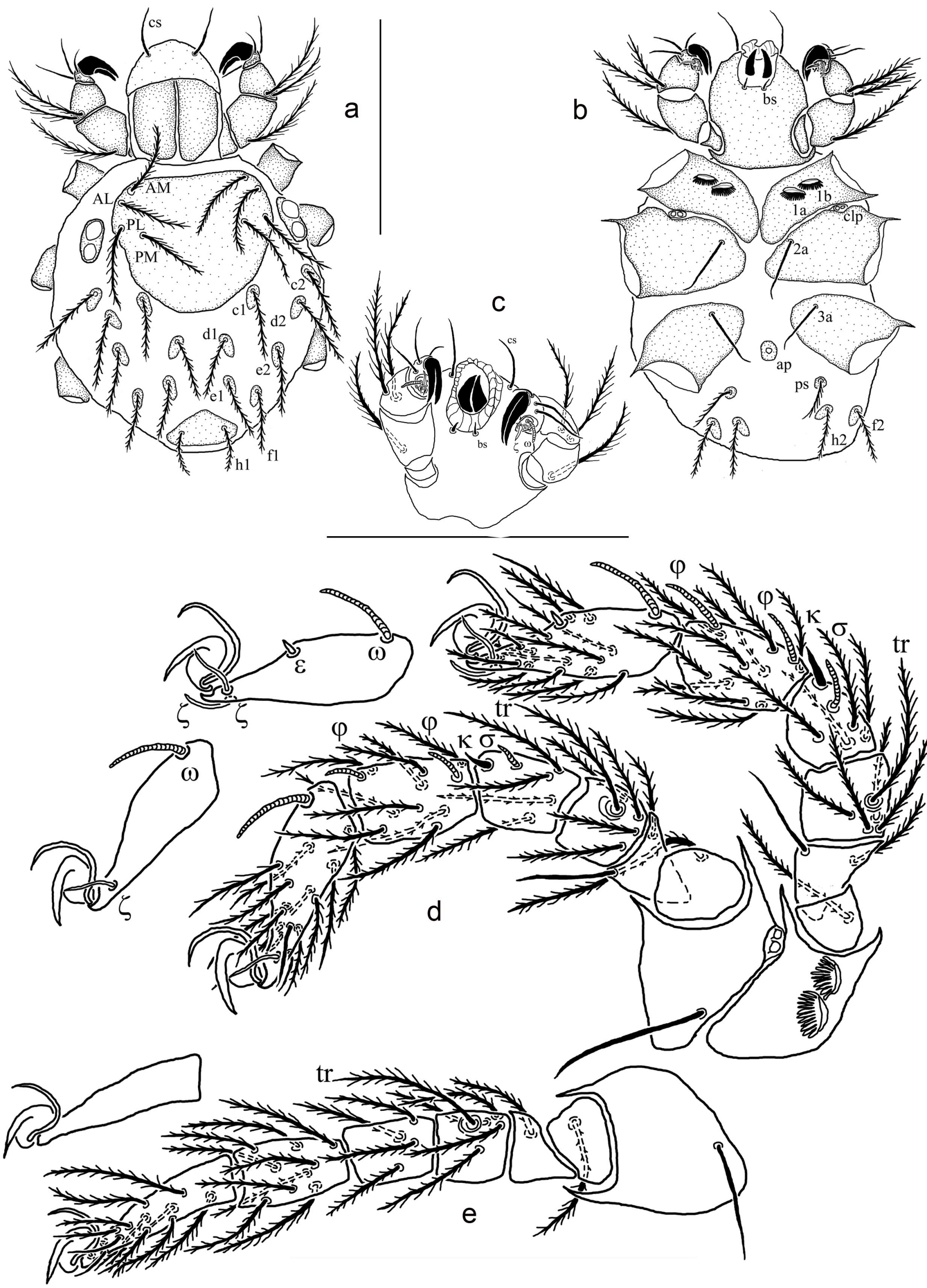



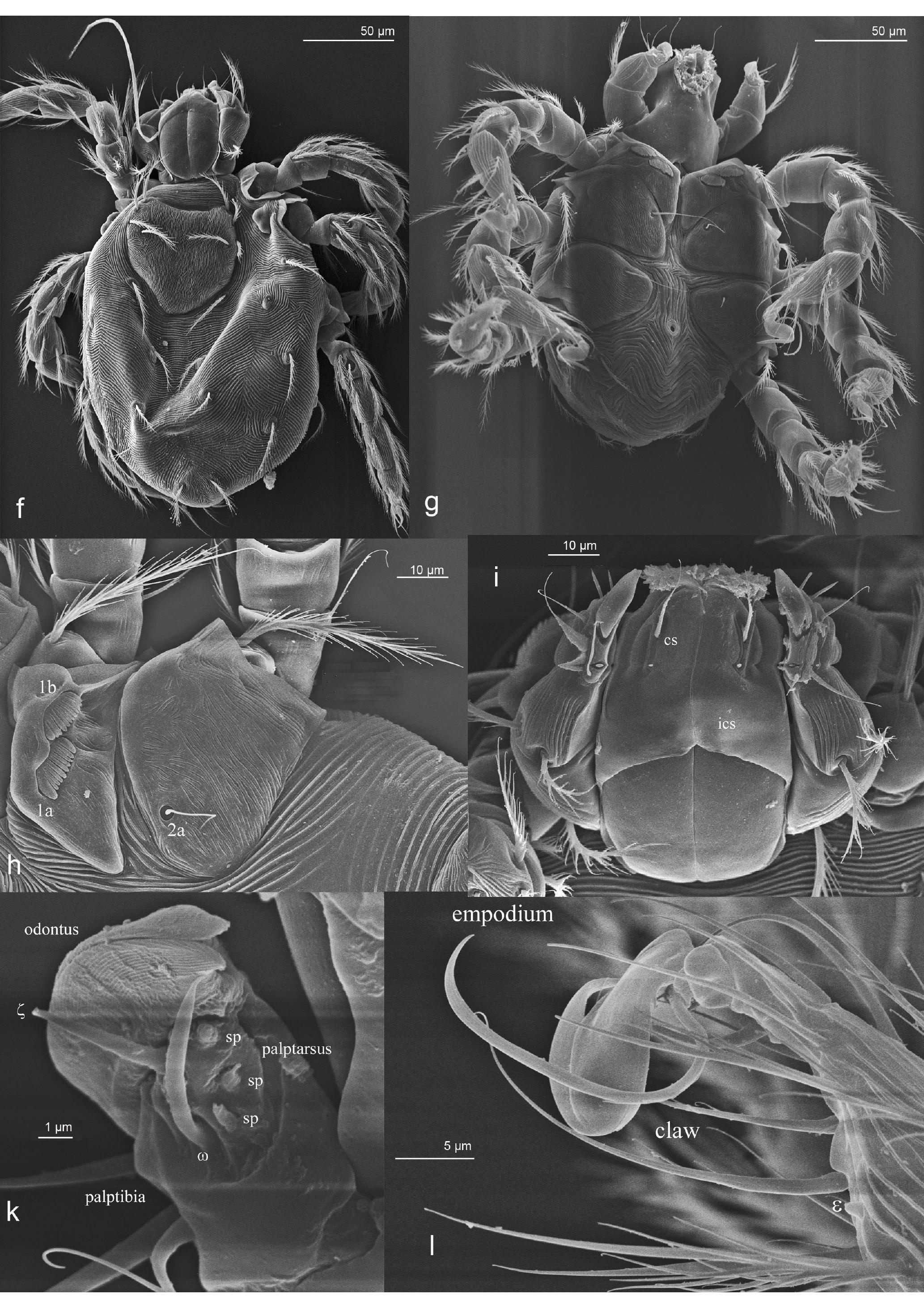


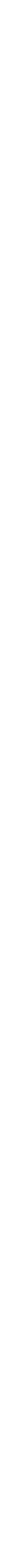




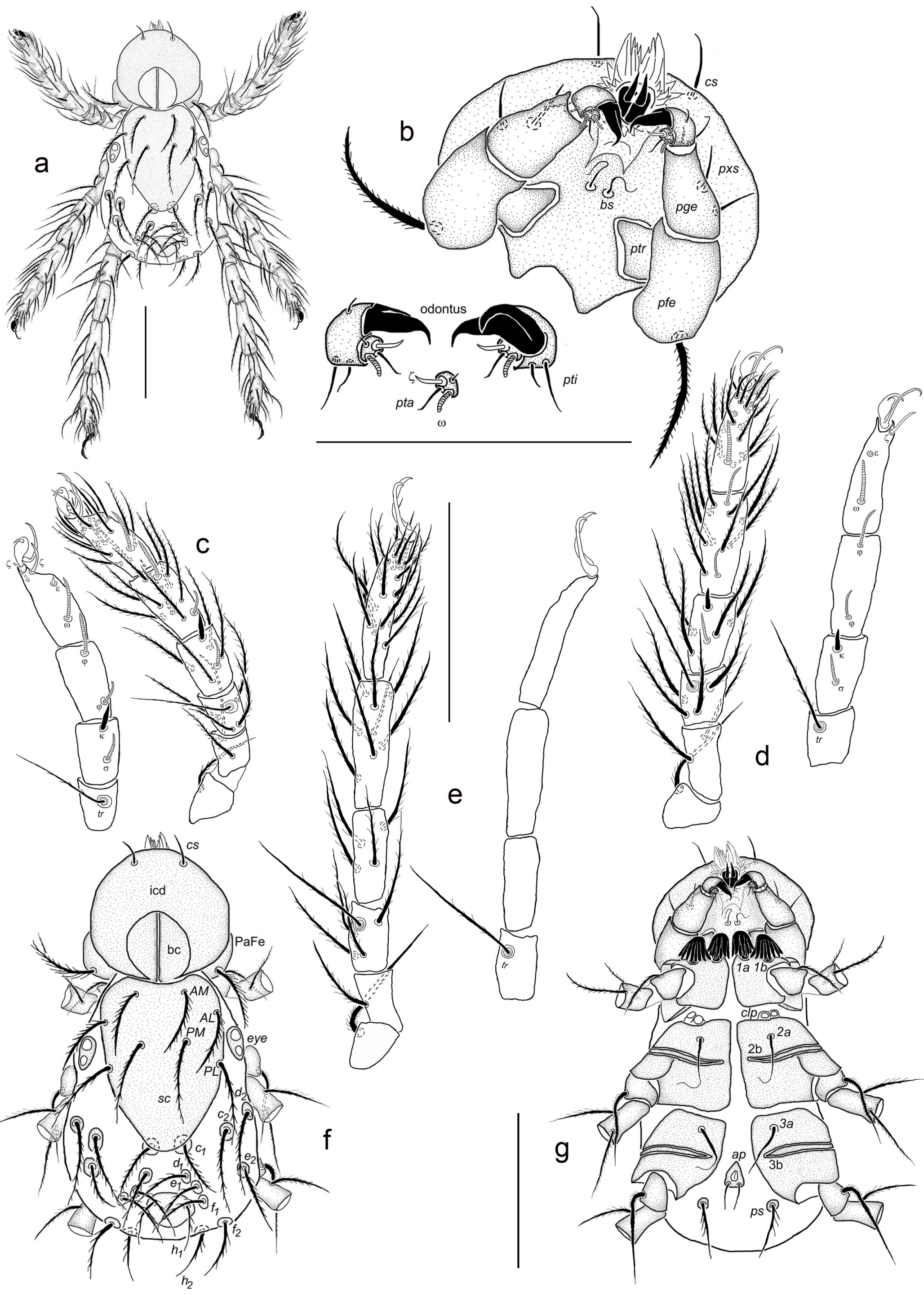




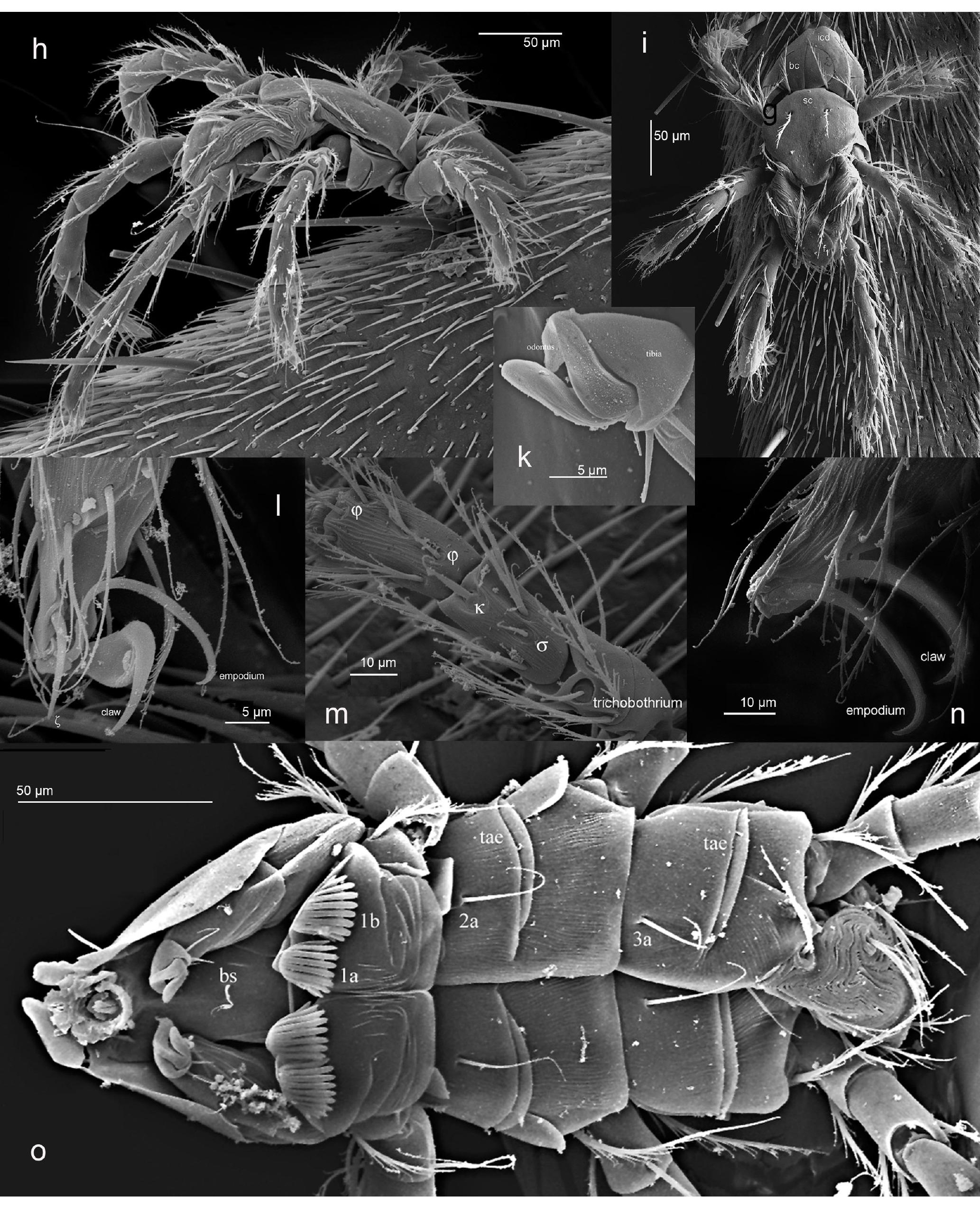




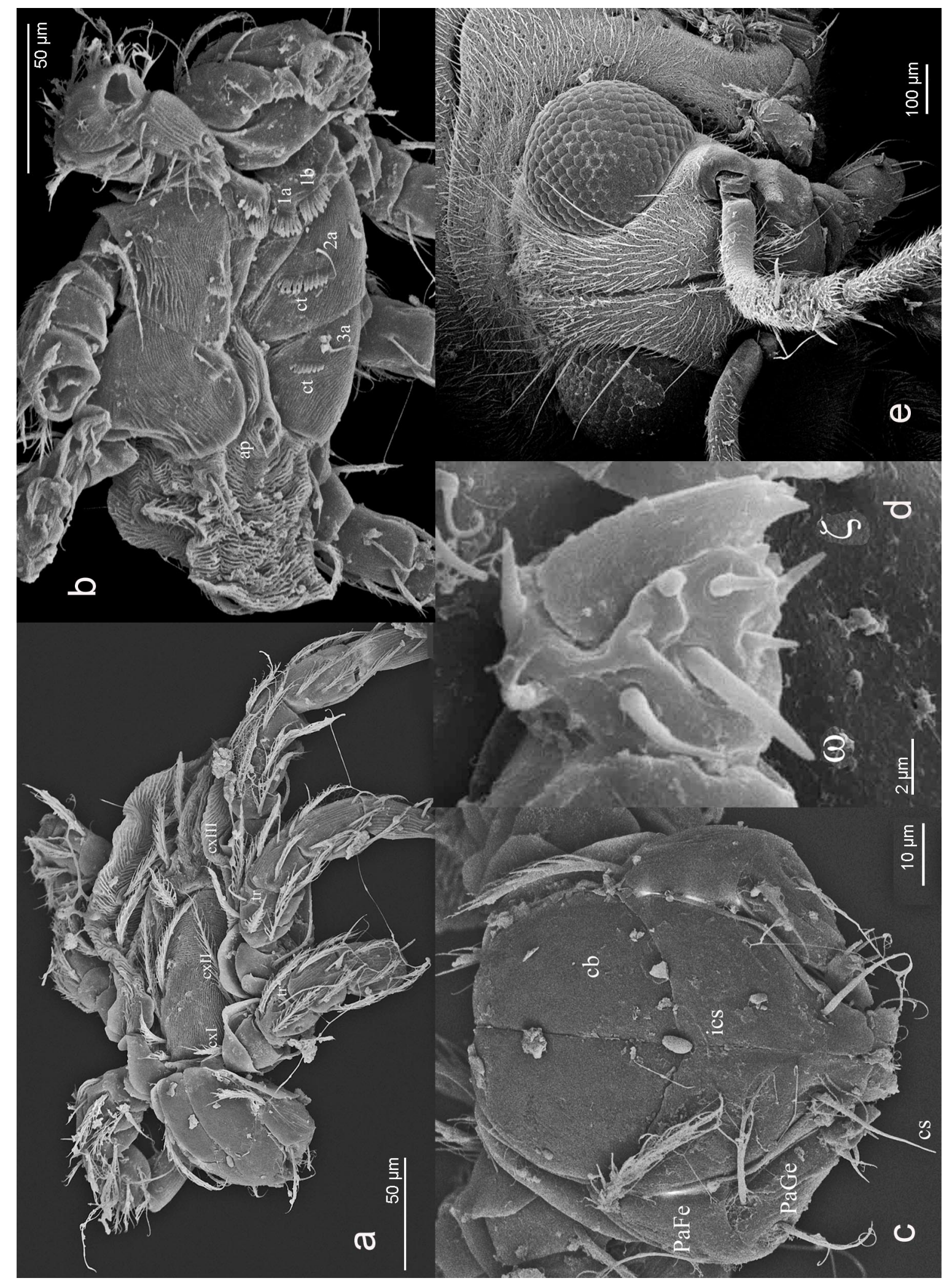




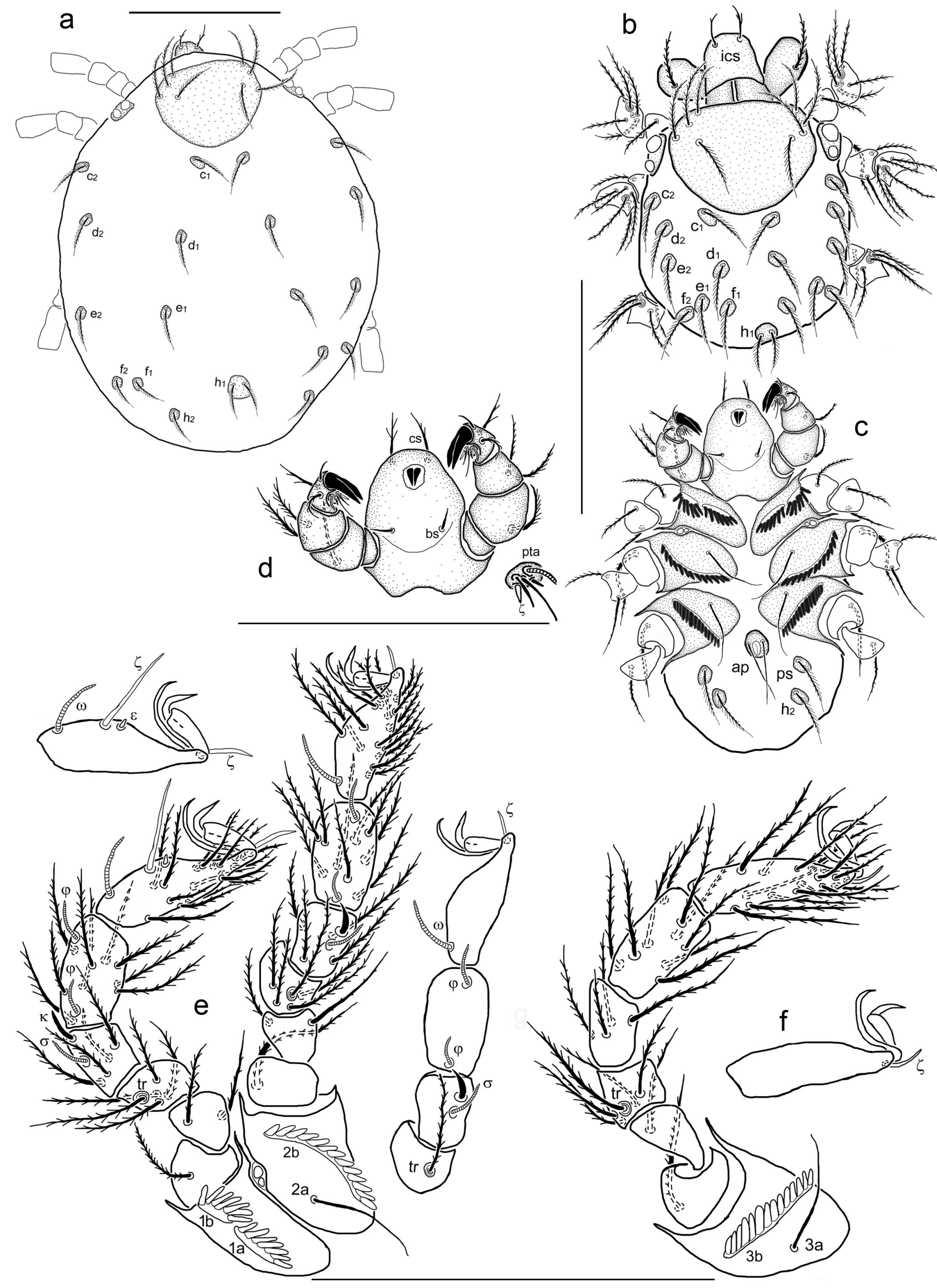




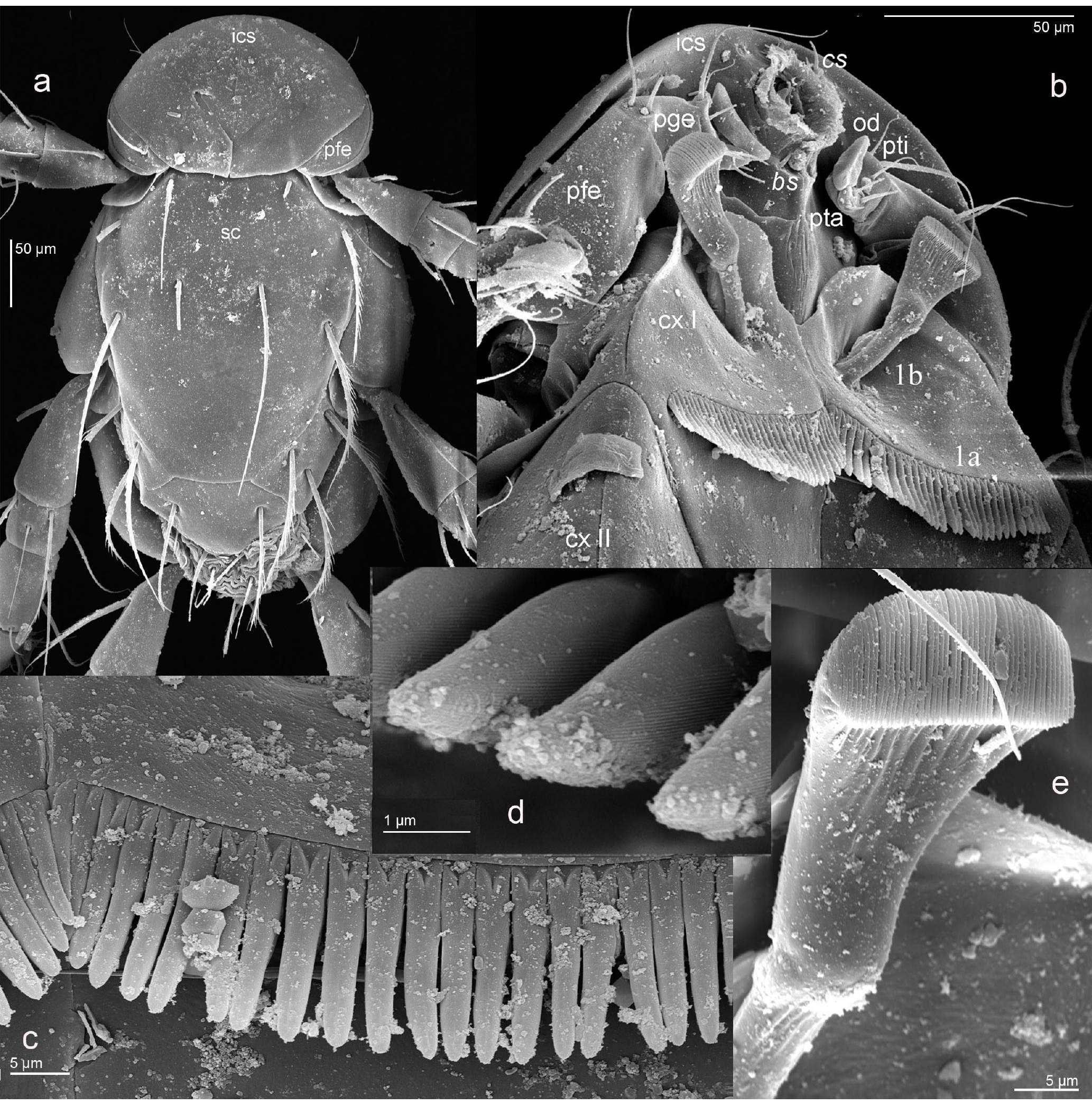




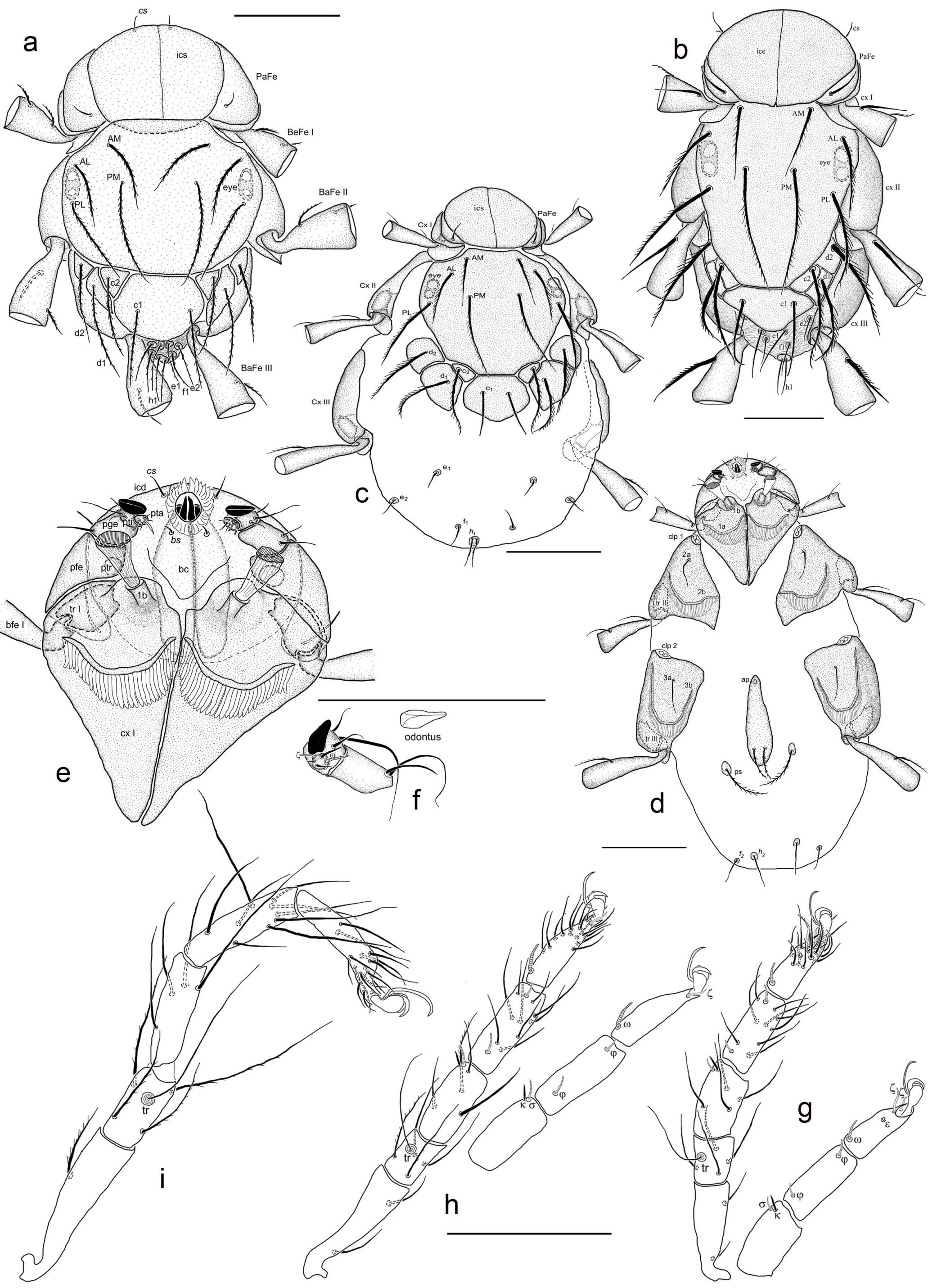




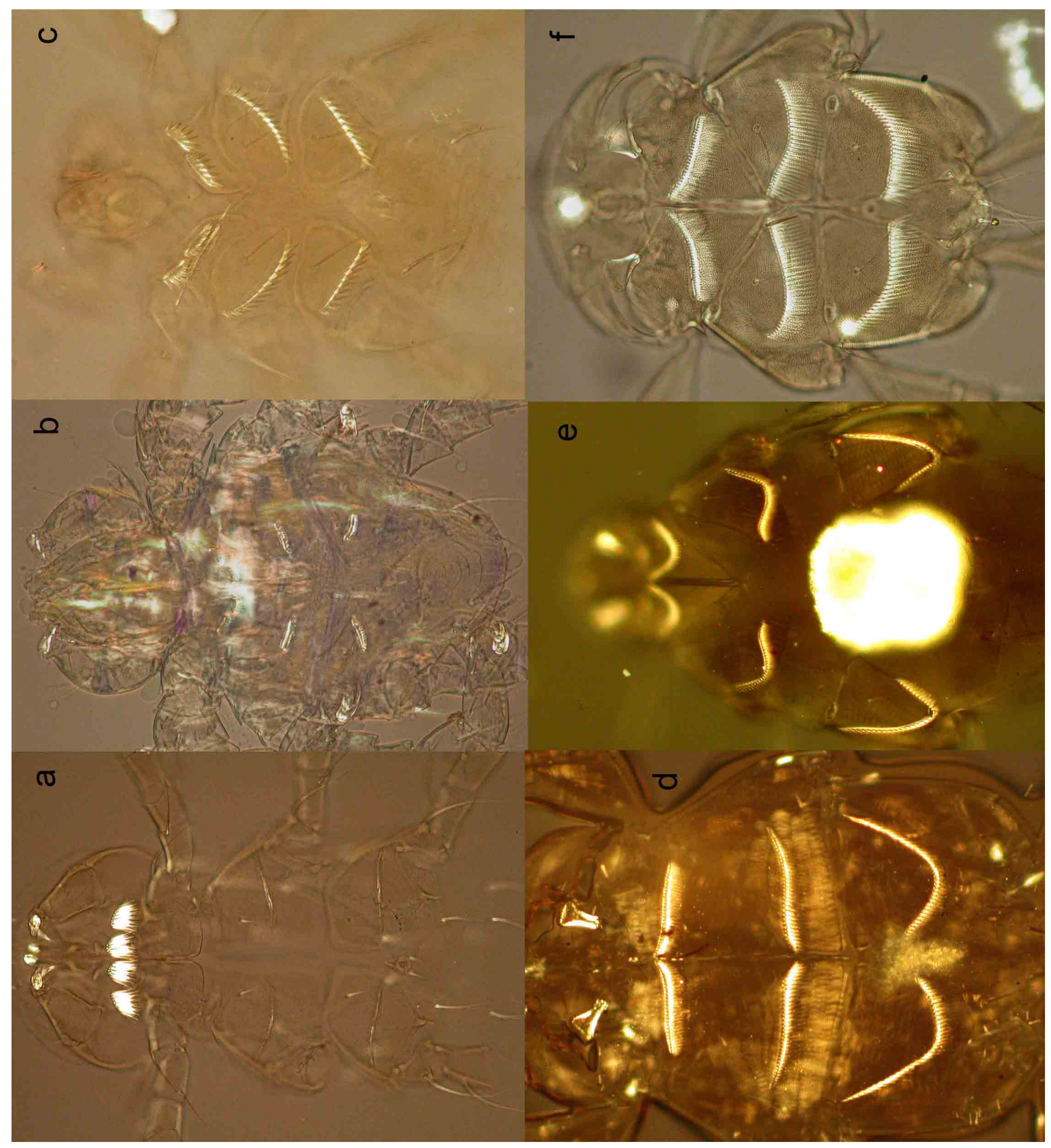

